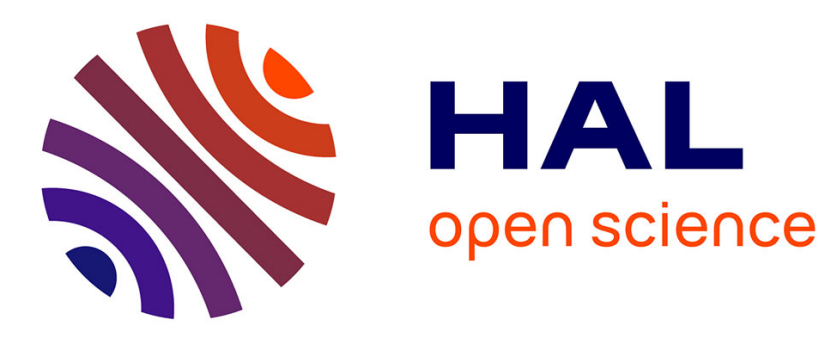

\title{
Direct Simulation of a Solidification Benchmark Experiment
}

Tommy Carozzani, Charles-André Gandin, Hugues Digonnet, Michel Bellet, Kader Zaidat, Yves Fautrelle

\section{- To cite this version:}

Tommy Carozzani, Charles-André Gandin, Hugues Digonnet, Michel Bellet, Kader Zaidat, et al.. Direct Simulation of a Solidification Benchmark Experiment. Metallurgical and Materials Transactions A, 2013, 44 (2), pp.873-887. 10.1007/s11661-012-1465-1 . hal-00747567

HAL Id: hal-00747567

https://hal-mines-paristech.archives-ouvertes.fr/hal-00747567

Submitted on 25 Apr 2014

HAL is a multi-disciplinary open access archive for the deposit and dissemination of scientific research documents, whether they are published or not. The documents may come from teaching and research institutions in France or abroad, or from public or private research centers.
L'archive ouverte pluridisciplinaire HAL, est destinée au dépôt et à la diffusion de documents scientifiques de niveau recherche, publiés ou non, émanant des établissements d'enseignement et de recherche français ou étrangers, des laboratoires publics ou privés. 


\title{
Direct Simulation of a Solidification Benchmark Experiment
}

\author{
TOMMY CAROZZANI, CHARLES-ANDRÉ GANDIN, HUGUES DIGONNET, \\ MICHEL BELLET, KADER ZAIDAT, and YVES FAUTRELLE
}

\begin{abstract}
A solidification benchmark experiment is simulated using a three-dimensional cellular automaton-finite element solidification model. The experiment consists of a rectangular cavity containing a $\mathrm{Sn}-3 \mathrm{wt}$ pct $\mathrm{Pb}$ alloy. The alloy is first melted and then solidified in the cavity. A dense array of thermocouples permits monitoring of temperatures in the cavity and in the heat exchangers surrounding the cavity. After solidification, the grain structure is revealed by metallography. X-ray radiography and inductively coupled plasma spectrometry are also conducted to access a distribution map of $\mathrm{Pb}$, or macrosegregation map. The solidification model consists of solutions for heat, solute mass, and momentum conservations using the finite element method. It is coupled with a description of the development of grain structure using the cellular automaton method. A careful and direct comparison with experimental results is possible thanks to boundary conditions deduced from the temperature measurements, as well as a careful choice of the values of the material properties for simulation. Results show that the temperature maps and the macrosegregation map can only be approached with a three-dimensional simulation that includes the description of the grain structure.
\end{abstract}

DOI: $10.1007 / \mathrm{s} 11661-012-1465-1$

(C) The Minerals, Metals \& Materials Society and ASM International 2012

\section{INTRODUCTION}

MACROSEGREGATION is defined by composition heterogeneities of alloying elements in cast parts, measured over a volume larger than the microstructure. It forms during solidification processing and remains a major concern for the casting industry. As reported in a dedicated review, ${ }^{[1]}$ the origin of macrosegregation is multifold: (1) solute transport in the free liquid and in the mushy zone due to fluid flow, (2) grain transport because of gravity and convection, (3) liquid flow driven by shrinkage and deformation, and (4) diffusion of solute in the liquid and solid phases. Because these mechanisms most often overlap, great difficulty is found in assessing the magnitude of each mechanism on a measured macrosegregation map.

The studies of macrosegregation were first conducted at the end of the 1960s and the beginning of the 1970s..$^{[2-8]}$ The role of the density variation between the solid and the liquid phases, known as shrinkage, was named inverse segregation. The effect of gravity-driven buoyancies was identified as the main cause for natural convection of the melt because of the presence of temperature and composition variations. Finally, the role of the deformation of the solid phase in the presence of a mushy zone was also presented. A discussion based

TOMMY CAROZZANI, Ph.D. Student, CHARLES-ANDRÉ GANDIN, CNRS Research Fellow, HUGUES DIGONNET, Research Fellow, and MICHEL BELLET, Professor, are with the Mines ParisTech CEMEF UMR 7635, 06904 Sophia Antipolis, France. Contact e:mail: Charles-Andre.GANDIN@mines-paristech.fr KADER ZAIDAT, Research Fellow, and YVES FAUTRELLE, Professor, are with the Institut National Polytechnique de Grenoble SIMAP UMR 5266, 38402 Saint Martin d'Hères, France

Manuscript submitted May 20, 2012. on mathematical modeling, which summarizes all mechanisms, was proposed by Lesoult et al..$^{[9]}$

The experiment developed by Hebditch and Hunt in $\mathrm{Pb}-\mathrm{Sn}$ alloys serves as a reference for the current study. ${ }^{[8]}$ It was presented in details in Hebditch's Ph. D. work. ${ }^{[10]}$ A similar experiment was recently redeveloped with enhanced data acquisition and metallurgical inspection. ${ }^{[11,12]}$ The objective was to provide quantitative measurements for comparison with numerical simulation of solidification. An attempt was already done to simulate the experiment for a Sn-10 wt pet $\mathrm{Pb}$ alloy. ${ }^{[13]}$ However, it suffered from its two-dimensional (2D) approximation as well as measurement uncertainties.

In this contribution, we propose quantitative comparison of solidification simulations with a selected macrosegregation benchmark experiment in a Sn-3 wt pct $\mathrm{Pb}$ alloy. ${ }^{[12]}$ The experimental procedure is first briefly presented. It is followed by a description of the model developed to solve volume average conservation equations, first without and then with the grain structure. The coupling methodology with thermodynamic data and solidification paths is also explained in detail. Finally, simulation results are shown and compared with the measurements of the macrosegregation benchmark experiment.

\section{EXPERIMENTAL}

A schematic of the apparatus developed for the solidification benchmark experiment is presented in Figure 1. It consists of a parallelepipedic cavity with dimensions $\quad 100-\mathrm{mm}$ width $\times 60-\mathrm{mm}$ height $\times 10-\mathrm{mm}$ thickness. The crucible is made of a $0.5-\mathrm{mm}$ thick stainless steel sheet. The opposite smallest surfaces of the cavity, with dimensions $60 \mathrm{~mm} \times 10 \mathrm{~mm}$, are positioned 


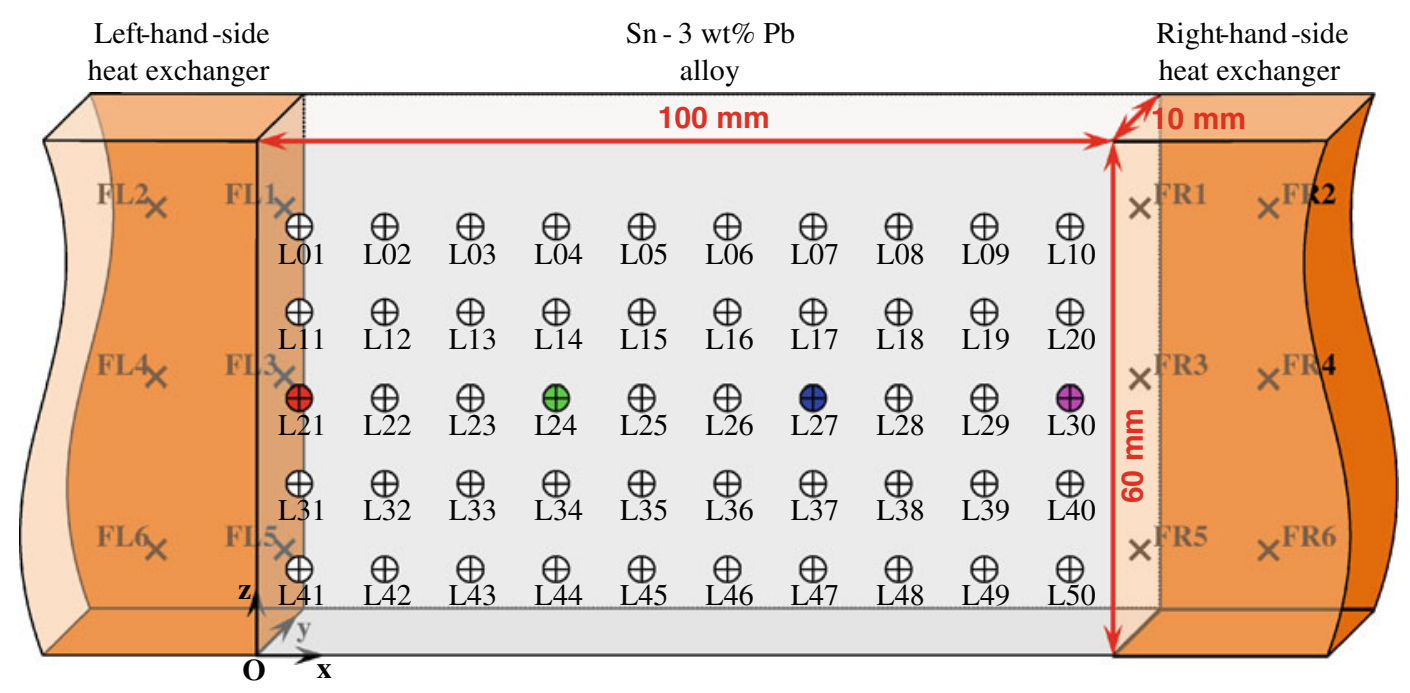

Fig. 1-Schematics of the experimental set-up developed for the solidification benchmark experiment of a Sn-3 wt pct $\mathrm{Pb}$ alloy ${ }^{[1,12]}$ with position and label of the 62 thermocouples used in the analysis.

vertically. They are maintained into contact with a lefthand-side (LHS) and a right-hand-side (RHS) heat exchanger made of copper. Each heat exchanger is composed of two parts. The first part is a superposition of a heating element positioned around the copper element. The second part is composed of a water box with precisely controlled temperature. Both heat exchangers are equipped with $6 \mathrm{~K}$-type thermocouples to impose heating, holding, and cooling time sequences that serve to melt or freeze the alloy contained in the cavity. The thermocouples are identified with symbol $\times$ in Figure 1 and labeled from FL1 to FL6 and FR1 to FR6 for the LHS and RHS heat exchangers, respectively. Experiments are performed under vacuum, of the order of $1 \mathrm{kPa}$, thus avoiding heat exchange through air convection. Heat loss by radiation is compensated by a Kirchhoff box so that thermal insulation conditions can be assumed for the largest surfaces as well as for the top surface of the cavity. The bottom surface of the cavity is insulated with an aerogel insulator, the thermal conductivity of which is around $0.02 \mathrm{~W} \mathrm{~m}^{-1} \mathrm{~K}^{-1}$ at $473.15 \mathrm{~K}\left(200{ }^{\circ} \mathrm{C}\right)$. As a consequence of these configurations, a quasi $2 \mathrm{D}$ temperature field can be assumed. ${ }^{[11]}$

A sample of $\mathrm{Sn}-3$ wt pet $\mathrm{Pb}$ alloy is placed in the cavity. It is first heated and kept at $533.15 \mathrm{~K}\left(260{ }^{\circ} \mathrm{C}\right)$ for 600 seconds. The objective is to melt and homogenize the liquid. An electromagnetic stirring device located under the crucible is used during this uniform temperature holding period to create forced convection and to mix the melt. Stirring is then stopped, and time is reset to zero. The RHS heat exchanger is heated up to $553.15 \mathrm{~K}\left(280{ }^{\circ} \mathrm{C}\right)$, while the LHS heat exchanger is cooled down to $513.15 \mathrm{~K}\left(240{ }^{\circ} \mathrm{C}\right)$. These temperatures are maintained for 1000 seconds so that natural convection due to the temperature difference between the LHS and RHS heat exchangers becomes the only origin for fluid flow and to settle a stable convection regime. As will be shown later, stability is indeed deduced from the temperature measurements in the cavity. Finally, the RHS and LHS heat exchangers are simultaneously cooled down at $-0.03 \mathrm{~K} \mathrm{~s}^{-1}$ until complete solidification, so that a $40-\mathrm{K}$ difference is maintained between the LHS and RHS heat exchangers during the entire solidification experiment.

Temperature evolution in the cavity is recorded with $50 \mathrm{~K}$-type thermocouples equally spaced by $10 \mathrm{~mm}$ in a regular lattice of 5 rows $\times 10$ columns. Their position is identified with symbol $\oplus$ and labels numbered from L01 to L50 in Figure 1. The thermocouples are not directly located into contact with the alloy but welded on one of the largest surfaces of the steel sheets, with dimensions $100 \mathrm{~mm} \times 60 \mathrm{~mm}$. In accordance with the assumption of perfect insulation conditions along those surfaces, such measurements permit reconstructing the time evolution of the $2 \mathrm{D}$ temperature map on the surface of the crucible, with a frequency of $1 \mathrm{~Hz}$. The grain structure of the solidified ingot is revealed by standard metallographic procedures, including mechanical polishing for an etching duration ranging from 10 to 15 minutes with a mixture of 75 pet vol. $\mathrm{HCl}$ and 25 pct vol. $\mathrm{HNO}_{3}$. After etching, the sample was wiped with cotton soaked in this mixture for 1 minute and finally dried. The final segregation map is deduced from X-ray imaging and quantitative chemical analyses using Inductively Coupled Plasma (ICP) spectrometry. For the latter analysis, 2-mm cylindrical holes are drilled through the entire $10-\mathrm{mm}$ thickness of the $\mathrm{Sn}-3$ wt pct $\mathrm{Pb}$ sample. The holes are centered at the same 50 positions where the thermocouples were located. The chips retrieved for each hole are analyzed by ICP. As a result, an average $2 \mathrm{D}$ segregation map can be drawn from the volumetric measurements, defined by its $100 \mathrm{~mm}^{2}$ surface resolution and its $70 \mathrm{~mm}^{3}$ individual volume measurements. All experimental results in this presentation are extracted from Reference 12. 


\section{MODELING}

The model presented in the current study is an extension of previous studies developed for the simulation of grain structure and segregation in alloy solidification. ${ }^{[14-23]}$

\section{A. Solution for Heat and Solute Mass Transfer}

Averaging is used over a representative volume $V_{0}$ containing an alloy defined by a mixture of chemical species distributed in a mixture of phases. ${ }^{[2,25]}$ Each phase $\alpha$ is characterized by its density, $\rho^{\alpha}$, and its volume, $V^{\alpha}$. Its volume fraction is defined by $g^{\alpha}=V^{\alpha} /$ $V_{0}$. The average of a quantity per unit mass, $\xi$, over volume $V_{0},\langle\rho \xi\rangle$, is defined by the summation over all phases of the intrinsic average quantity over the phase volume, $\langle\rho \xi\rangle^{\alpha}$, weighted by the volume fraction of the phase, $\langle\rho \xi\rangle=\sum_{\alpha} \mathrm{g}^{\alpha}\langle\rho \xi\rangle^{\alpha}$. With this definition and assuming a binary mixture, a constant and equal density for all phases, $\rho_{0}$, and fixed solid phases, average conservation equations can be derived for energy, solute mass, total mass, and momentum ${ }^{[20]}$.

$$
\begin{gathered}
\rho_{0}\left(\frac{\partial\langle H\rangle}{\partial t}+\langle\mathbf{v}\rangle \cdot \nabla\langle H\rangle^{l}\right)-\nabla \cdot(\langle\kappa\rangle \nabla T)=0 \\
\frac{\partial\langle w\rangle}{\partial t}+\langle\mathbf{v}\rangle \cdot \nabla\langle w\rangle^{l}-\nabla \cdot\left(D^{l} g^{l} \nabla\langle w\rangle^{l}\right)=0 \\
\nabla \cdot\langle\mathbf{v}\rangle=0
\end{gathered}
$$$$
\rho_{0} \frac{\partial\langle\mathbf{v}\rangle}{\partial t}+\frac{\rho_{0}}{g^{l}} \nabla \cdot(\langle\mathbf{v}\rangle \times\langle\mathbf{v}\rangle)=\nabla \cdot\left(\mu^{l} \nabla\langle\mathbf{v}\rangle\right)-g^{l} \nabla p^{l}
$$$$
+g^{l} \rho^{l} \mathbf{g}-\mathbf{M}
$$

The unknown parameters of these equations are the average enthalpy, $\langle H\rangle$, the average mass fraction of the solutal species, $\langle w\rangle$, the average velocity, $\langle\mathbf{v}\rangle$, and the intrinsic liquid pressure $p^{l}$. Superscript $l$ denotes the liquid phase, $t$ is the time, $T$ is the temperature, $\langle\kappa\rangle$ is the average thermal conductivity, and $D$ is the diffusion coefficient for the solutal species. Note that in Eq. [2], diffusion in the solid phase has been omitted at the scale of the representative volume. In all equations, the average velocity is given by $\langle\mathbf{v}\rangle=g^{l}\langle\mathbf{v}\rangle^{l}$ as a fixed solid phase is assumed $\left(\mathbf{v}^{s}=0\right)$. The Boussinesq approximation is used to compute the fluid flow induced by natural convection as a solution of the momentum equation. The density is therefore kept constant in all terms of Eq. [4], but in the term proportional to the gravity vector $\mathbf{g}$ : $\rho^{l}=\rho_{0}\left(1-\beta_{T}\left(T-T_{0}\right)-\beta_{w}\left(\langle w\rangle^{l}-w_{0}^{l}\right)\right)$ where $\beta_{T}$ and $\beta_{w}$ are the thermal and solutal expansion coefficients, and $T_{0}$ and $w_{0}^{l}$ are reference temperature and composition, respectively. The volumetric friction force $\mathbf{M}$ accounts for the interaction of the liquid phase with the solid phase. It is defined as $\mathbf{M}=\left(\mu^{l} / K\right) g^{l}\langle\mathbf{v}\rangle$ where $\mu$ is the dynamic viscosity, and $K$ is the local permeability given by $K=\left[g^{l^{3}} \lambda_{2}^{2}\right] /\left[180\left(1-g^{l}\right)^{2}\right] .^{[29]}$ In the fully liquid region, $K$ tends toward infinity, and the classical
Navier-Stokes equation is retrieved. In the solid region, $K$ tends toward zero, and $\mathbf{M}$ becomes dominant, leading to Darcy's relation. In a mushy zone, $K$ mainly depends on the secondary dendrite arm spacing, $\lambda_{2}$. In the current study, the value of $\lambda_{2}$ is directly extracted from measurements ${ }^{[12]}$ and is kept constant during the calculations. This approximation is not strictly valid as the permeability is known to be an anisotropic property that varies with the spacing seen in the various flow directions. ${ }^{[26-28]}$ Thus, not only the primary and secondary dendrite arm spacings should be used, but also the crystallographic orientation of each grain. While the latter is available in the current model, the lack of detailed measurements that distinguishes the primary and secondary dendrite arm spacings has led to the preference of the above relationship with a single parameter.

Equations [1], [2] and [3], [4] are solved with a finite element method and a staggered scheme to compute the average enthalpy, $\langle H\rangle$, the average composition, $\langle w\rangle$, the average intrinsic liquid pressure, $p^{l}$, and the average velocity, $\langle\mathbf{v}\rangle$. Triangular and tetrahedral elements are used in 2D and in 3D, respectively. Details of the formulations and numerical algorithms are given in Reference 29.

\section{B. Modeling of Grain Structure}

Prediction of the grain structure is part of the current model. Only the reaction-nucleation and growth-of one primary solid phase is considered. The latter is simply identified as the first solid phase formed below the liquidus temperature of the alloy with local average solute composition $\langle w\rangle$. It is further assumed that the solid takes a dendritic morphology, as indeed observed in the hypoeutectic $\mathrm{Sn}-\mathrm{Pb}$ system. The reaction of other microstructures upon further cooling is not described hereafter. For instance, the nucleation and growth of the eutectic microstructure is not directly simulated. Its formation, i.e., the volume fraction of its two phases in a binary system, is yet described based on the assumption of an invariant thermodynamic transformation as will be shown later.

Nucleation sites of the primary solid phase are spatially distributed in the volume of the melt and at the surfaces with the mold. Their density follows Gaussian distributions of the melt undercooling, with parameters $\left(n_{\max }^{S}, \Delta T_{n}^{S}, \Delta_{\sigma}^{S}\right)$ for the surface and $\left(n_{\text {Max }}^{V}, \Delta T_{n}^{V}, \Delta_{\sigma}^{V}\right)$ for the volume. ${ }^{[15]}$ The mean undercooling, $\Delta T_{n}$, the standard deviation, $\Delta T_{\sigma}$, and the total density of nucleation sites that corresponds to the integral of the distribution over undercooling, $n_{\max }$, are adjustable parameters of the model that can be deduced from dedicated measurements. ${ }^{[30]}$ The volume of the alloy is simply multiplied by $n_{\mathrm{Max}}^{V}$ to compute the total number of nucleus. Random distribution in space is then performed to allocate all the nuclei. A critical nucleation undercooling is also randomly attributed to each nucleus according to the Gaussian distribution parameters $\Delta T_{n}^{V}$ and $\Delta T_{\sigma}^{V}$. The same procedure is applied for the surfaces where nucleation is set to take place, considering $n_{\text {Max }}^{S}$ and the surface of the walls 
where nucleation is set to take place, with parameters $\Delta T_{n}^{S}$ and $\Delta T_{\sigma}^{S}$. Upon cooling, if melt is still present at the location of the nucleation site, and if its undercooling is higher than the critical nucleation undercooling, then a new grain is created. A random crystallographic orientation given by a set of three Euler angles is then attributed to the grain. It characterizes the crystallographic orientation of the grain and thus the dendrite growth directions, assumed here to follow $\langle 100\rangle$ directions.

A velocity of the dendrite tips, $v_{p}$, is computed. It defines the growth kinetics of the half diagonals of an octahedral shape associated with a portion of the envelope of the growing grain. A supersaturation, $\Omega$, is defined by the difference between the dendrite tip composition, $w^{l s}$, and the average liquid composition far from the interface, $w^{l \infty}$ :

$$
\Omega=\left(w^{1 \mathrm{~s}}-w^{1 \infty}\right) /\left(w^{\mathrm{ls}}(1-k)\right)
$$

It is computed from a boundary layer correlation:

$$
\begin{aligned}
\Omega= & P_{v_{p}} \exp \left(P_{v_{p}}\right)\left\{E_{l}\left(P_{v_{p}}\right)\right. \\
& \left.-E_{l}\left(P_{v_{p}}\left[1+4\left(A \operatorname{Re}_{2 r}^{B} \mathrm{Sc}^{C} \sin (\theta / 2)\right)^{-1}\right]\right)\right\}
\end{aligned}
$$

with $A=0.5773, B=0.6596, C=0.5249$, and where $P_{v_{p}}=\left(r v_{p}\right) /\left(2 D^{l}\right)$ is the growth Péclet number defined with the dendrite tip radius $r, P_{v^{l}}=\left(r \cdot v^{l}\right) /\left(2 D^{l}\right)$ is the flow Péclet number proportional to the liquid velocity, $v^{l}, \mathrm{Sc}=v / D^{l}$ is the Schmidt number defined with the kinematic viscosity $v, \operatorname{Re}_{2 r}=4 P_{v_{1}} / \mathrm{Sc}$ is the Reynolds number, $\theta$ is the angle between the fluid flow direction and a $\langle 100\rangle$ growth direction. ${ }^{[31]}$ In practice, composition $w^{l \infty}$ is approximated by the average composition $\langle w\rangle$. The velocity of the dendrite tip is computed with the relation given by the marginal stability criterion ${ }^{[32]}$ :

$$
r^{2} v_{p}=\frac{D^{l}}{\sigma^{*}} \frac{\Gamma}{m_{\mathrm{L}}(k-1) w^{l s}}
$$

with $m_{\mathrm{L}}$ the liquidus slope, $k$ the segregation coefficient, $\Gamma$ the Gibbs-Thomson coefficient, and $\sigma^{*}$ a stability constant equal to $\left(4 \pi^{2}\right)^{-1} \cdot{ }^{[19,21]}$ The algorithm used to solve Eqs. [5] through [7] is detailed in Reference 31. It should be pointed out that several dendrite tip growth kinetics models are found in the literature. In particular, the effect of the anisotropy of the interfacial energy can be implemented in the analysis, ${ }^{[33]}$ and the curvature and attachment kinetics can also be included. ${ }^{[32]}$ However, the latter have minor effects on the growth kinetics in the range of low undercooling investigated in the current study; so Eqs. [5] through [7] provide a simple and efficient approximation to include the effect of the supersaturation, the alloy composition, and the fluid flow intensity and orientation.

Several zones $(z)$, can coexist upon the development of the dendritic microstructure. ${ }^{[34-36]}$ The "free" liquid or extradendritic liquid, also referred to as melt and identified by $(z)=(0)$, and a zone made of a dendritic solid plus interdendritic phases, identified by $(z)=(1)$. Note that when the latter interdendritic phase is a liquid, the zone is then referred to as mushy zone. The current model extends zone (1) to describe the alloy up to room temperature when no liquid is left and various interdendritic microstructures and phases can be present. Initially, only the melt is present with volume fraction $g^{(0)}=1$, and there is no mushy zone, $g^{(1)}=0$. The volume fraction of the mushy zone increases upon the development of the grain structure. The value $g^{(1)}=1$ corresponds to a mushy state, in which case, the dendritic grain structure is fully developed. Intermediate values of $g^{(1)}$ correspond to a transition state made of a mixture of a mushy zone, $g^{(1)}$, plus an extradendritic liquid, $g^{(0)}=1-g^{(1)}$. Thus, the value of $g^{(1)}$ depends on nucleation events and growth kinetics as described above, and more generally on evolutions of the temperature, average composition, and fluid flow velocity.

The reaction kinetics is integrated with the help of a $3 \mathrm{D}$ cellular automaton (CA) method. ${ }^{[23]}$ The cellular automaton algorithms are built on a regular lattice of cubic cells superimposed onto the FE mesh. The size of the unit cell lattice is smaller than the FE mesh size. The propagation of the mushy zone is tracked at the scale of the cell lattice. It takes place by nucleation and growth. For nucleation, cells are used to distribute the nuclei and their critical undercooling. It is therefore at the center of a liquid cell that undercooling is computed by interpolation of the temperature field deduced at the FE nodes. If the cell undercooling is larger than the nucleation undercooling, then a new grain forms. The octahedral shape is centered with the cell center. It grows with the kinetics given by Eqs. [5] through [7]. The mushy zone fraction of the cell is no longer zero. It is computed considering the ratio between the octahedral growing shape and the volume required to capture all neighboring cells. Thus, it increases upon growth of the octahedral shape. When the growing cell captures the center of a neighboring liquid cell, the latter also starts to grow, and its mushy zone fraction also departs from zero. Finally, the mushy zone fraction of all cells is summed up to provide the average information at the FE nodes, $g^{(1)}$. Details of the nucleation and growth algorithms can be found elsewhere. ${ }^{[14-16,23]}$.

\section{Coupling with Thermodynamic Equilibrium Calculations}

The dendritic grain structure is characterized by a single primary solid phase, and its propagation defines the presence of the mushy zone in the simulation domain. However, other phases are present in the mushy zone. This is clear upon reading the phase diagram of the Sn$\mathrm{Pb}$ system provided in Figure 2 where regions labeled LIQ, BCT, and FCC stand for the stability domains of the phases with original database names LIQUID, BCT_A5, and FCC_A1, respectively. Upon cooling of $\mathrm{Sn}-3$ wt pet $\mathrm{Pb}$ alloy, primary dendritic solidification of the BCT phase happens below the liquidus temperature, $T_{\mathrm{L}}=500.83 \mathrm{~K} \quad\left(227.68^{\circ} \mathrm{C}\right)$. With full equilibrium, solidification ends at the solidus temperature, $T_{\mathrm{S}}=476.15 \mathrm{~K}\left(203{ }^{\circ} \mathrm{C}\right)$, i.e., above the eutectic temperature, $T_{\mathrm{E}}=454.56 \mathrm{~K}\left(181.41{ }^{\circ} \mathrm{C}\right)$. The mushy zone forming between $T_{\mathrm{L}}$ and $T_{\mathrm{S}}$ thus only consists of BCT 


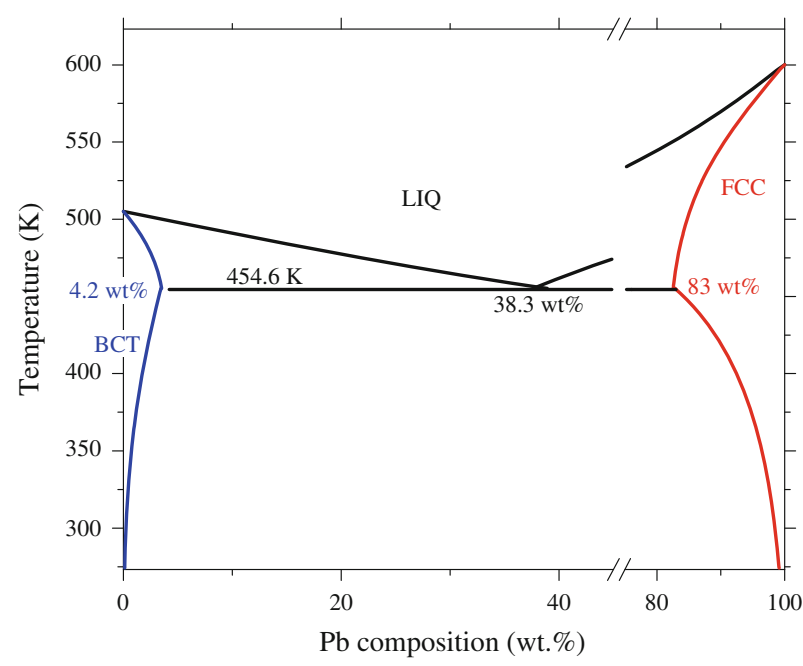

Fig. 2-Phase diagram of the $\mathrm{Sn}-\mathrm{Pb}$ system as computed with ThermoCalc ${ }^{[46]}$ using the PBIN thermodynamic database ${ }^{[47]}$ with label of the stability domains of individual phases.

plus LIQ, i.e., an interdendritic liquid. Because solidification is completed above $T_{\mathrm{E}}$, no interdendritic eutectic microstructure is expected. However, FCC forms from $\mathrm{BCT}$ because of solid-state phase transformation upon cooling below the solvus temperature at $422.33 \mathrm{~K}$ $\left(149.18{ }^{\circ} \mathrm{C}\right)$. A local isothermal phase transformation model is thus required for the conversion of the average enthalpy, $\langle H\rangle$, and the average composition, $\langle w\rangle$, computed from the FE solution, into the temperature, $T$, and the volume fraction of each phase $\alpha$ in zone $(z), g^{\alpha^{(z)}}$. This is achieved based on the following definitions of average quantities and volume fractions:

$$
\begin{gathered}
\langle H\rangle=\sum_{(z)} \sum_{\alpha} g^{(z)} g^{\alpha^{(z)}}\langle H\rangle^{\alpha^{(z)}} \\
\langle w\rangle=\sum_{(z)} \sum_{\alpha} g^{(z)} g^{\alpha^{(z)}}\langle w\rangle^{\alpha^{(z)}} \\
\forall z, \sum_{\alpha} g^{\alpha^{(z)}}=1 \\
\sum_{(z)} g^{(z)}=1
\end{gathered}
$$

where $\langle H\rangle^{\alpha^{(z)}}$ and $\langle w\rangle^{\alpha^{(z)}}$ are the average enthalpy and composition of phase $\alpha$ in zone $(z)$, respectively.

The free melt represented by zone (0) can only consist of the liquid phase, LIQ, and consequently $g^{\mathrm{LIQ}}{ }^{(0)}$ $(\langle w\rangle, T)=1, g^{\mathrm{BCT}^{(0)}}(\langle w\rangle, T)=0$ and $g^{\mathrm{FCC}^{(0)}}(\langle w\rangle, T)=0$. Note that the latter values satisfy Eq. [10]. For the mushy zone (1), it is assumed that the cooling rate applied during the current experiment is sufficiently low to permit full equilibrium (or lever rule) approximation. Thus, for a given average composition of the alloy, $\langle w\rangle$, a unique phase transformation path is tabulated as a function of the temperature. This takes the form of the volume fraction of the phases $\alpha, g^{\alpha^{(1)}}(\langle w\rangle, T)$, and their average $\mathrm{Pb}$ composition $\langle w\rangle^{\alpha^{(1)}}(\langle w\rangle, T)$. Examples of tabulations for $g^{\alpha^{(1)}}(\langle w\rangle, T)$ and $\langle w\rangle^{\alpha^{(1)}}(\langle w\rangle, T)$ are presented in Figures 3(a) and (b), respectively, for two alloy compositions. For the 3 wt pct $\mathrm{Pb}$, the previous description of the start and end temperatures for the transformations are retrieved by following the thick dashed lines in Figure 3(a). Corresponding information is also provided as thick dashed lines in Figure 3(b) for the compositions of the phases. Note that Figure 3(b) partly reproduces the lines in Figure 2, as full equilibrium is assumed and the phase compositions simply correspond to the monovariant lines of the binary phase diagram. A second example is given in Figure 3 for alloy Sn-5 wt pct $\mathrm{Pb}$. Because the alloy composition is above the solubility limit of $\mathrm{Pb}$ in $\mathrm{BCT}$, i.e., $4.2 \mathrm{wt}$ pct $\mathrm{Pb}$ as read in Figure 2, the primary solidification of BCT is followed by an invariant eutectic reaction. As a consequence, FCC is expected to form abruptly from the eutectic temperature. This is also retrieved by the thin plain lines in Figure 3(a). It is also clear that this tabulation satisfies Eq. [10]. Finally, because the compositions of all phases $\alpha$ are tabulated in the mushy zone (1) as a function of the average composition $\langle w\rangle$ and temperature $T,\langle w\rangle^{\alpha^{(1)}}=\langle w\rangle^{\alpha^{(1)}}(\langle w\rangle, T)$, and because only the liquid phase exists in zone (0), the phase composition $\langle w\rangle^{\mathrm{LIQ}^{(0)}}$ can be computed from Eq. [9]. Knowing all phase compositions at a given temperature, tabulated average enthalpy of phases is used for application to Eq. [8]. These tabulations only depend on the phase composition and temperature, $\langle H\rangle^{\alpha^{(z)}}=$ $\langle H\rangle^{\alpha}\left(\langle w\rangle^{\alpha^{(z)}}, T\right)$. Tabulations are provided in Figure 3(c). Consequently, for a unique set of $\langle H\rangle,\langle w\rangle$ and $g^{(z)}$, a unique temperature exists that satisfies Eqs. [8] through [11]. It is sought for owing to the tabulations by means of an appropriate lookup procedure.

Note that the ranges of the tabulations in Figure 3 cover the entire experiment (i.e., from initial superheat down to room temperature, and from minimum to maximum $\mathrm{Pb}$ composition defined for each phase). All reactions that take place upon cooling from a liquid state to room temperature of the Sn-3 wt pct $\mathrm{Pb}$ alloy are thus accounted for, including solid-state transformations. Also the range for the average composition is such that it covers the entire hypoeutectic phase diagram, from pure Sn to the eutectic composition, 38.3 wt pet $\mathrm{Pb}$, thus permitting the description of possible macrosegregation.

There are several advantages that are present in the current tabulation procedure: Variations of heat capacities and heat of transformations with temperature and composition are implicitly taken into account. It is not limited to the binary eutectic phase diagram shown in Figure 2 and can be used for multicomponent alloys with several peritectic and eutectic reactions. Material properties become dependent on phase compositions and phase fractions, the latter being considerably changed because of macrosegregation. Such methodology was shown earlier to provide advantages when quantitative 


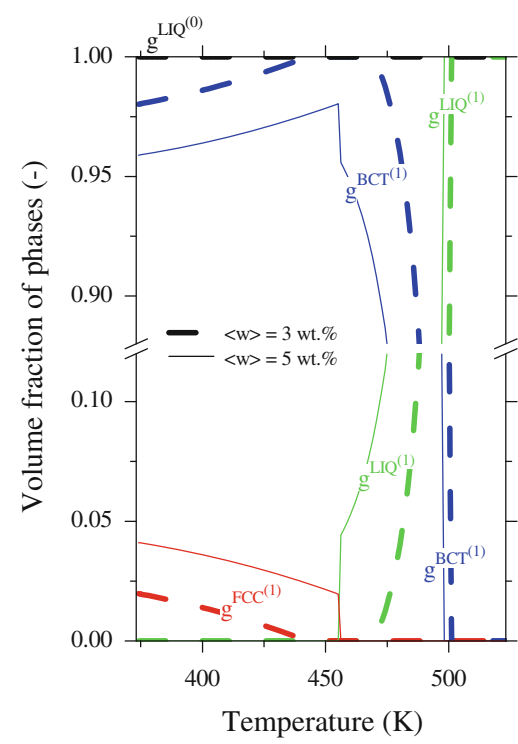

(a)

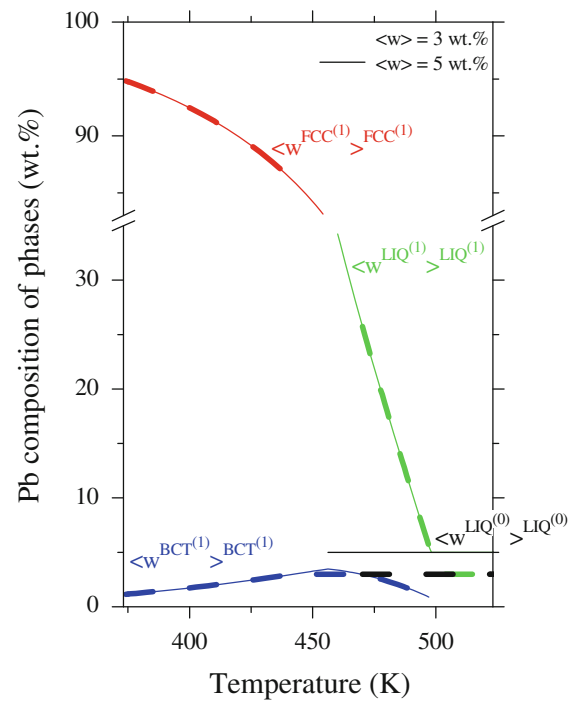

(b)

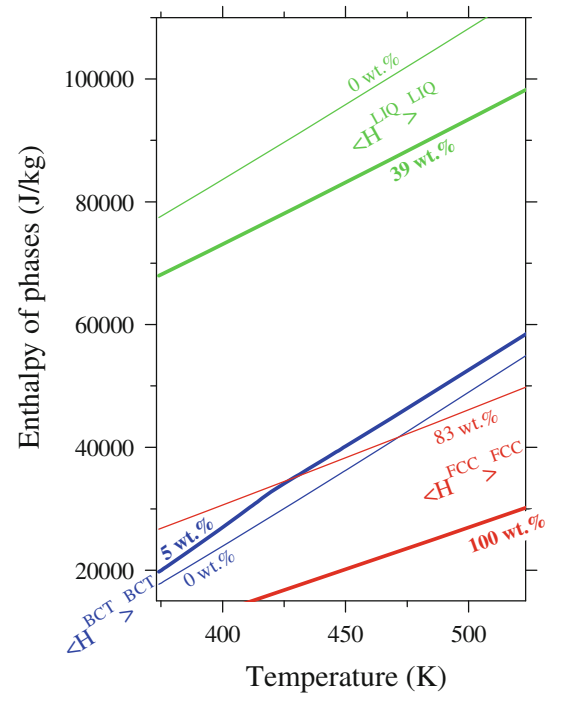

(c)

Fig. 3-Tabulations with temperature, for alloys Sn-3 wt pet $\mathrm{Pb}$ and $\mathrm{Sn}-5 \mathrm{wt}$ pet $\mathrm{Pb}$, of phase data: $(a)$ volume fraction, $(b)$ composition, and (c) enthalpy. Data extracted from the PBIN database ${ }^{[47]}$ using ThermoCalc ${ }^{[46]}$ and assuming full equilibrium.

comparison with measurements is to be reached. ${ }^{[35]}$ Please note that this methodology does not directly track the fraction of eutectic that was solidified, although the information can be retrieved locally as the equilibrium fraction formed because of the invariant reaction. It was shown that the methodology based on tabulation of thermodynamic data can be used to include tracking of the eutectic reaction ${ }^{[23]}$ as a second zone, $(z)=(2)$, formed in the remaining liquid.

\section{RESULTS AND DISCUSSION}

Conditions for solving Eqs. [1] through [4] by means of the FE method over the simulation domain are given in Table I and are explained hereafter. The simulation domain is defined by the parallelepipedic cavity that contains the Sn-3 wt pet $\mathrm{Pb}$ alloy. An almost uniform temperature, from $530.25 \mathrm{~K}$ to $532.15 \mathrm{~K}\left(257.1{ }^{\circ} \mathrm{C}\right.$ to $259.0{ }^{\circ} \mathrm{C}$ ), is measured by the 50 thermocouples L01-L50 shown in Figure 1 at the time selected for the start of the simulation. Therefore, the imposed initial temperature is $T_{0}=531.75 \mathrm{~K}\left(258.6^{\circ} \mathrm{C}\right)$. According to Figure 2 , the initial state is a superheated melt, corresponding to $g_{0}^{\text {LIQ }}=1$ for $\left\langle w_{0}\right\rangle^{\text {LIQ }}=\left\langle w_{0}\right\rangle=3$. The tabulations given in Figure 3(c) thus permit a direct initialization of the average enthalpy of the system $\left\langle H_{0}\right\rangle=\langle H\rangle^{\text {LIQ }}$ $\left(\left\langle w_{0}\right\rangle^{\text {LIQ }}, T_{0}\right)$. The liquid velocity was not measured. Because of the absence of temperature gradient and assumption of no initial composition variation, initial convection is neglected, $\left\langle v_{0}\right\rangle=0 \mathrm{~m} \mathrm{~s}^{-1}$. Zero flux conditions are given at all surfaces of the simulation domain for solute mass and total mass. This is obviously required for mass conservation. A zero flow velocity is also imposed on all boundaries. For heat transfer, all boundaries are adiabatic, but the left and right surfaces in contact with the heat exchangers. Temperatures are imposed on these boundaries as Dirichlet conditions that need to be evaluated because of contact resistances between the heat exchangers and the ingot. For this purpose, at a given time, recording at thermocouples FL1 and FL2 at height $z=50 \mathrm{~mm}$ gives access to a flux in the LHS heat exchanger, i.e., $q=-\kappa^{\mathrm{Cu}}\left(T_{\mathrm{FLI}}-T_{\mathrm{FL} 2}\right) /$ $\left(x_{\mathrm{FLI}}-x_{\mathrm{FL} 2}\right)$ where $\left(x_{\mathrm{FLI}}-x_{\mathrm{FL} 2}\right)=15 \mathrm{~mm}$ is the distance between the two thermocouples, and $k^{\mathrm{Cu}}=380 \mathrm{~W} \mathrm{~m}^{-1} \mathrm{~K}^{-1}$ is the thermal conductivity of copper. This flux is used together with the temperature recorded at the same height $(z=50 \mathrm{~mm})$ at thermocouple L01 to deduce the temperature $T_{\mathrm{FL} 1_{\text {in }}}$ in the alloy at the interface with the LHS heat exchanger, according to the relation $q=-\kappa^{1}\left(T_{\mathrm{L} 01}-T_{\mathrm{FL}_{1 \mathrm{in}}}\right) /\left(x_{\mathrm{L} 01}-x_{\mathrm{FL}_{1}}\right)$ where $\left(x_{\mathrm{L} 01}-x_{\mathrm{FL}_{1}}\right)=5 \mathrm{~mm}$ is the distance from thermocouple L01 to the interface, and $\kappa^{l}$ is the thermal conductivity of the alloy. This procedure is reproduced with thermocouples FL3, FL4, and L21 at $z=30 \mathrm{~mm}$; and FL5, FL6, and L41 at $z=10 \mathrm{~mm}$. The three temperatures $T_{\mathrm{FL} 1_{\text {in }}}, T_{\mathrm{FL} 3_{\text {in }}}$ and $T_{\mathrm{FL} 5_{\text {in }}}$ deduced in the alloy at the boundary with the LHS heat exchanger are then extrapolated along the whole $60-\mathrm{mm}$ height by fitting a quadratic polynomial function: $T_{\mathrm{FL}_{\text {in }}}(z)=$ $N_{1}(z) T_{\mathrm{FL}_{\text {in }}}+N_{3}(z) T_{\mathrm{FL}_{\text {in }}}+N_{5}(z) T_{\mathrm{FL}_{\text {in }}}$ with $N_{1}(z)=$ $(z-30)(z-50) / 800, N_{3}(z)=-(z-10)(z-50) / 400$

and $N_{5} \quad(z)=(z-10)(z-30) / 800$ in which $z$ is expressed in $\mathrm{mm}$. This procedure is repeated at each sampling time so that a tabulated temperature history can finally be deduced with the form $T_{\mathrm{FL}}(z, t)$ with $z \in[0 \mathrm{~mm}, 60 \mathrm{~mm}]$ and $t \in[0$ seconds, 5000 seconds $]$. The same procedure is applied for the RHS vertical boundary with thermocouples FR1-FR6, L10, L30, and L50 to deduce $T_{\mathrm{FR}_{\text {in }}}(z, t)$ that characterizes the time and space evolution of the temperature in the alloy at the boundary with the RHS heat exchanger. The tabulated values $T_{\mathrm{FL}_{\text {in }}}(z, t)$ and $T_{\mathrm{FR}_{\text {in }}}(z, t)$ are applied as Dirichlet 
Table I. Value of Material Properties and Simulation Parameters

\begin{tabular}{|c|c|c|c|}
\hline & Variable & Value & Unit \\
\hline \multicolumn{4}{|l|}{ Parameters for the FE model } \\
\hline Thermodynamic database & & PBIN & \\
\hline Diffusion of $\mathrm{Pb}$ in liquid $\mathrm{Sn}$ & $D^{1}$ & $3 \times 10^{-9}$ & $\mathrm{~m}^{2} \mathrm{~s}^{-1}$ \\
\hline Dynamic viscosity of the liquid & $\mu^{l}$ & $2 \times 10^{-3}$ & $\mathrm{~Pa} \mathrm{~s}$ \\
\hline Solutal expansion coefficient & $\beta_{w}$ & $-5.3 \times 10^{-3}$ & wt pet ${ }^{-1}$ \\
\hline Thermal expansion coefficient & $\beta_{T}$ & $9.5 \times 10^{-5}$ & $\mathrm{~K}^{-1}$ \\
\hline Reference temperature & $T_{0}$ & 501.29 & $\mathrm{~K}$ \\
\hline Reference composition & $w_{0}^{1}$ & 3 & wt pet \\
\hline Density & $\rho_{0}$ & 7130 & $\mathrm{~kg} \mathrm{~m}^{-3}$ \\
\hline Gravity field & g & -9.81 & $\mathrm{~m} \mathrm{~s}^{-2}$ \\
\hline Thermal conductivity in the solid & $\kappa^{s}$ & 55 & $\mathrm{~W} \mathrm{m^{-1 }} \mathrm{K}^{-1}$ \\
\hline Thermal conductivity in the liquid & $\kappa^{l}$ & 33 & 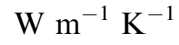 \\
\hline Secondary dendrite arm spacing & $\lambda_{2}$ & $90 \times 10^{-6}$ & $\mathrm{~m}$ \\
\hline Initial temperature & $T_{0}$ & 531.75 & $\mathrm{~K}$ \\
\hline Initial composition & $\left\langle w_{0}\right\rangle$ & 3 & wt pct \\
\hline Initial state & $g_{0}^{\mathrm{LIQ}}$ & 1 & - \\
\hline Initial velocity & $\left\langle v_{0}\right\rangle$ & 0 & $\mathrm{~m} \mathrm{~s}^{-1}$ \\
\hline FE mesh size & $l_{\mathrm{FE}}$ & $1200 \times 10^{-6}$ & $\mathrm{~m}$ \\
\hline Time step & $\Delta t$ & 0.1 & $\mathrm{~s}$ \\
\hline \multicolumn{4}{|c|}{ Additional parameters for the CA model } \\
\hline Melting temperature & $T_{\mathrm{M}}$ & 505.15 & K \\
\hline Segregation coefficient & $k$ & 0.0656 & wt pct \\
\hline Liquidus slope & $m_{\mathrm{L}}$ & -1.2895 & $\mathrm{~K}$ wt $\mathrm{pct}^{-1}$ \\
\hline Gibbs-Thomson coefficient & $\Gamma$ & $2 \times 10^{-7}$ & $\mathrm{~K} \mathrm{~m}$ \\
\hline \multicolumn{4}{|c|}{ Distribution of nucleation sites with undercooling } \\
\hline \multicolumn{4}{|c|}{ Surface S_RHS } \\
\hline Maximum & $n_{\mathrm{Max}}^{\mathrm{S} \text { RHS }}$ & $1 \times 10^{4}$ & $m^{-3}$ \\
\hline Mean & $\Delta T_{n}^{S}$ RHS & 1.5 & $\mathrm{~K}$ \\
\hline Standard deviation & $\Delta T_{\sigma}^{S_{-} \mathrm{RHS}}$ & 0.5 & K \\
\hline \multicolumn{4}{|l|}{ Volume V_I (Figs. 5, 7(b), 8(b)) } \\
\hline Maximum & $n_{\mathrm{Max}}^{\mathrm{V}-\mathrm{I}}$ & $1 \times 10^{8}$ & $m^{-3}$ \\
\hline Mean & $\left.\Delta T_{n}\right\rangle_{-}$ & 3.5 & $\mathrm{~K}$ \\
\hline Standard deviation & $\Delta T_{\sigma}^{n} \mathrm{~V}_{\mathrm{I}}$ & 0.5 & $\mathrm{~K}$ \\
\hline \multicolumn{4}{|c|}{ Volume V_II (Figs. 6, 7a, 7b, 8c, 9c, 10c) } \\
\hline Maximum & $n_{\mathrm{Max}}^{\mathrm{V}-\mathrm{II}}$ & $1 \times 10^{7}$ & $m^{-3}$ \\
\hline Mean & $\Delta T_{n}^{\mathrm{M}_{-} \mathrm{II}}$ & 5 & $\mathrm{~K}$ \\
\hline Standard deviation & $\Delta T_{\sigma}^{\mathrm{V}} \mathrm{II}$ & 0.5 & $\mathrm{~K}$ \\
\hline CA cell size & $l_{\mathrm{CA}}^{0}$ & $200 \times 10^{-6}$ & $\mathrm{~m}$ \\
\hline
\end{tabular}

imposed boundary conditions in the entire thickness $(y \in[0 \mathrm{~mm}, 10 \mathrm{~mm}])$.

At first, simulations are presented that do not account for the prediction of the grain structure. The shortcut in the above description of the complete model is simply obtained by deactivation of the grain structure model and by imposing constant values of the zones during the entire simulations, $g^{(0)}=0$ and $g^{(1)}=1$. With these values, the liquid phase follows the equilibrium fraction and composition given by the tabulation of Figure 3 for phase $\mathrm{LIQ}^{(1)}$. As a consequence, no undercooling can take place, and solidification starts at the local liquidus temperature defined by the local average composition $\langle w\rangle$. Simulation parameters for the FE solutions are given in the first part of Table I. The value of the secondary dendrite arm spacing is deduced from measurements conducted on metallographic cross sections of the experiments. ${ }^{[12]}$ Its only use in the model is for the determination of a permeability value $\mathrm{K}$ for the volumetric friction force $\mathbf{M}$ entering the momentum conservation Eq. [4]. Simulations are conducted in 3D as well as with a 2D Cartesian approximation. Results are provided as cooling curves in Figure 4, at positions L30, L27, L24, and L21, i.e., on the surface of the simulation domain $(y=0 \mathrm{~mm})$, at mid-height $(z=30 \mathrm{~mm})$ and at distances $x=5,35,65$, and $95 \mathrm{~mm}$ from the LHS of the ingot surface, respectively (Figure 1). In Figures 4(a) and (b), the thick gray curves are the imposed boundary conditions: $\quad F R 3_{\text {in }}=T_{\mathrm{FR}}(z=30 \mathrm{~mm}, \quad t)$ and $\mathrm{FL}_{\text {in }}=\mathrm{T}_{\mathrm{FL}}(z=30 \mathrm{~mm}, t)$, and the dashed color curves are the thermocouple measurements. The influence of the 2D approximation is accessible by comparing the black curves in Figures 4(a) with those in (b). During the initialization period when the liquid is held 1000 seconds with a $40 \mathrm{~K}$ temperature difference between the LHS and RHS heat exchangers, the difference $\mathrm{FL} 3_{\text {in }}-\mathrm{FR} 3_{\text {in }}$ does not reach $40 \mathrm{~K}$. This is due to the contact resistance between the heat exchangers and the alloy, thus justifying the strategy explained above to use Dirichlet boundary conditions with retrieved temperature evolutions. The simulated curves overall reproduce well the cooling histories below around $503.15 \mathrm{~K}$ 


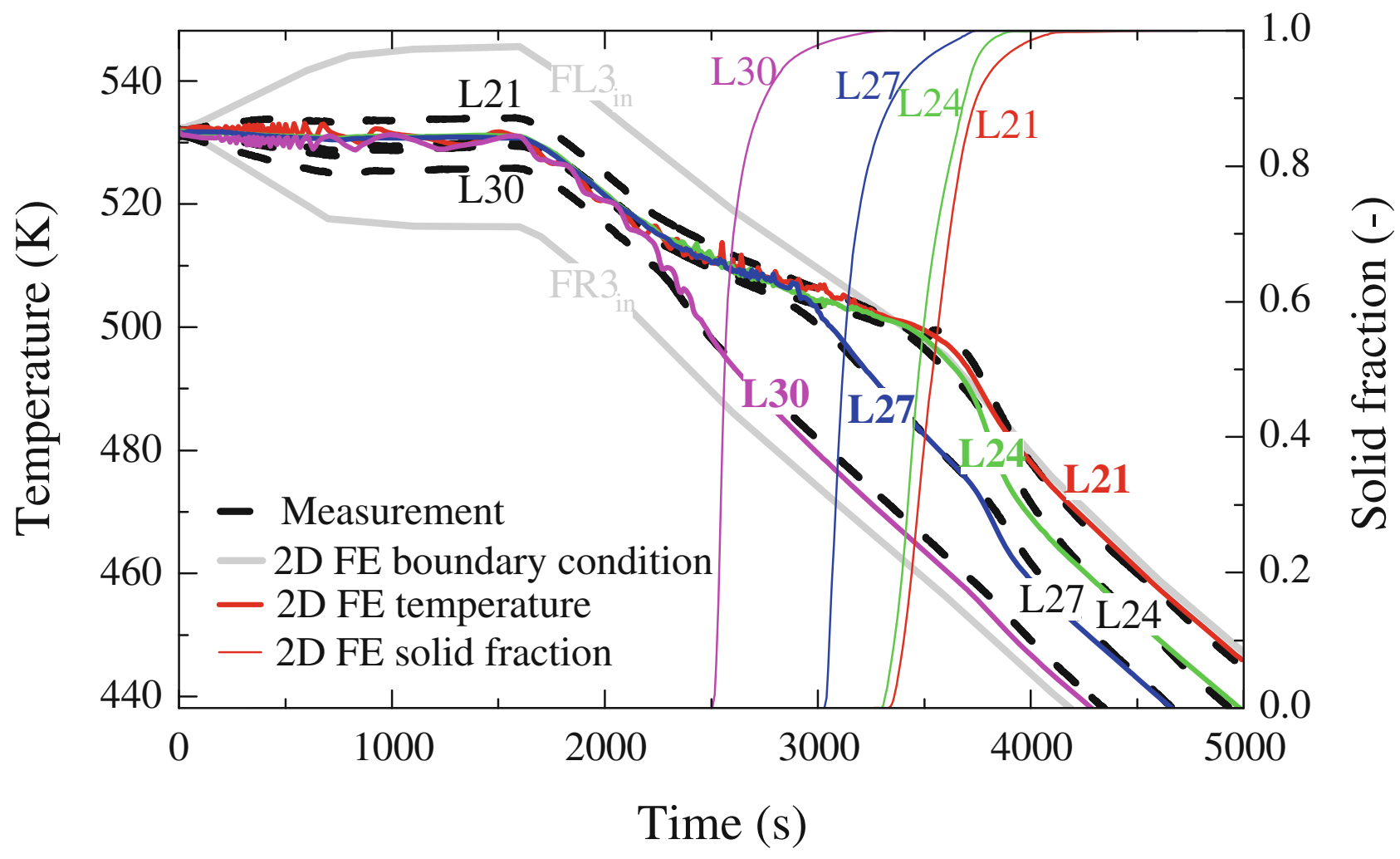

(a)

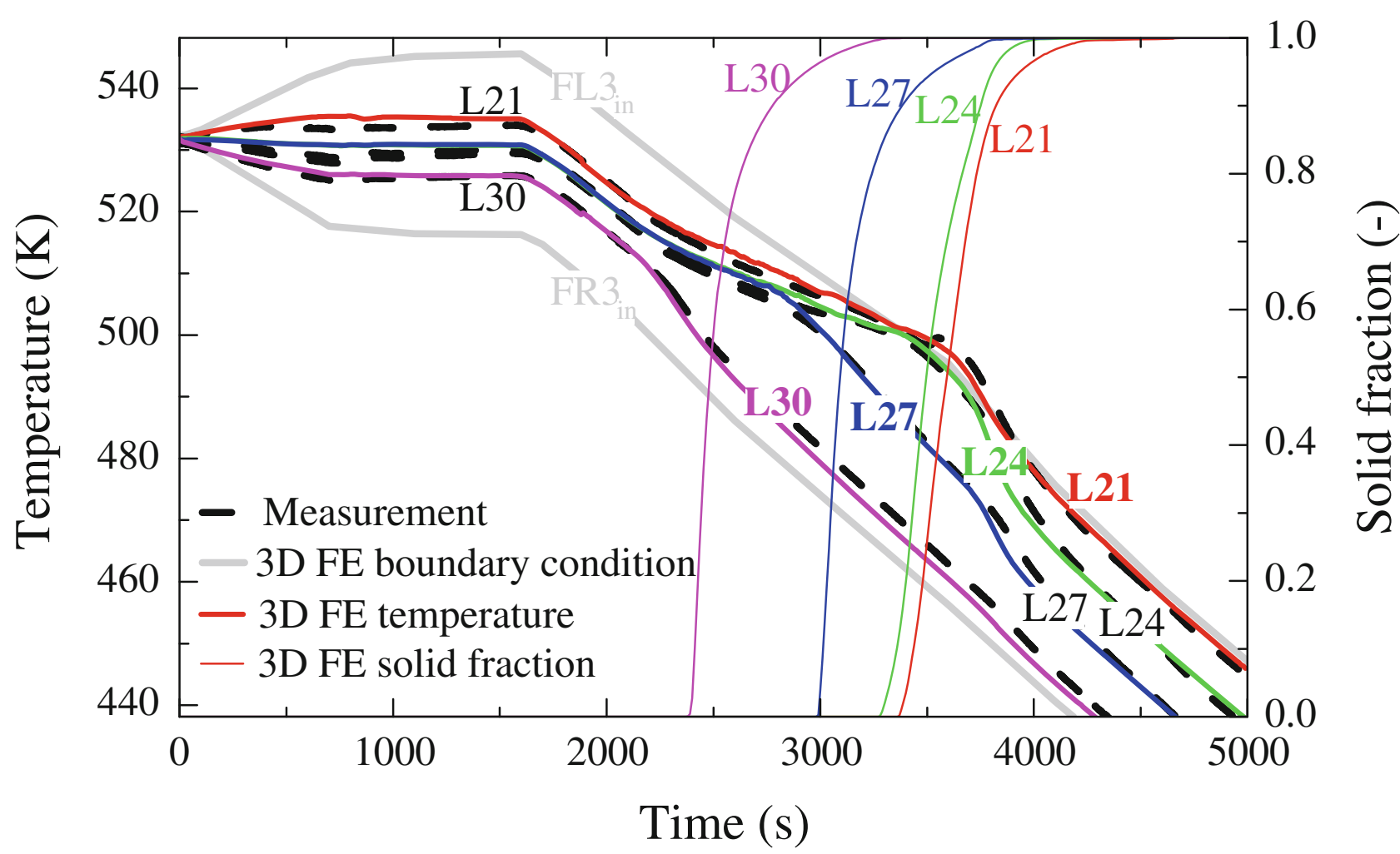

(b)

Fig. 4 - Comparison of (thick dashed lines) measured ${ }^{[12]}$ and (thick plain lines) computed cooling curves with $(a) 2 \mathrm{D}$ and $(b) 3 \mathrm{D}$ solutions of the FE model (without CA coupling). The computed time evolutions of the total fraction of solid phases are added as thin lines. 

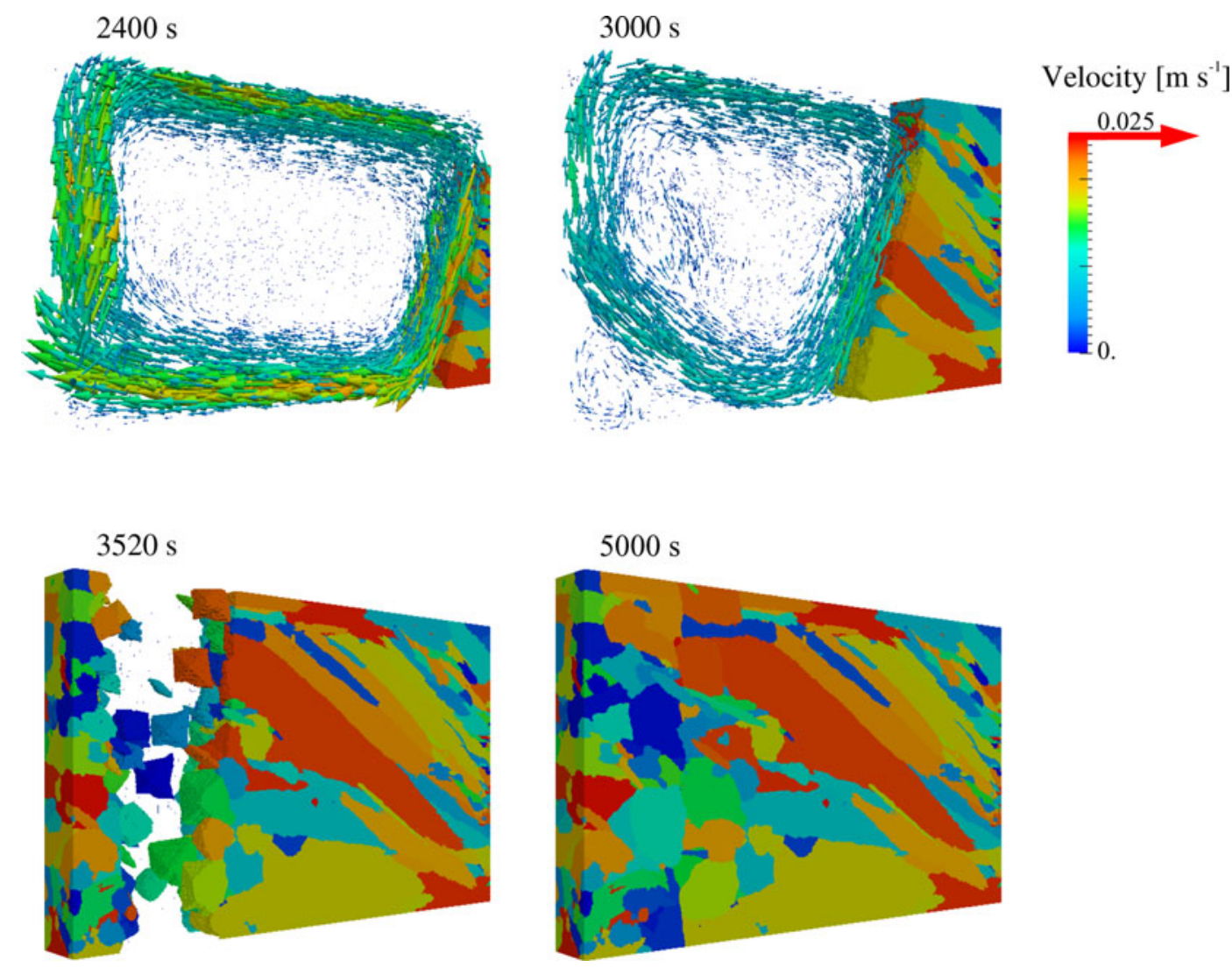

Fig. 5-3D CAFE simulation of the fluid flow and grain structure at different times during solidification of the $100 \mathrm{~mm} \times 60 \mathrm{~mm} \times 10 \mathrm{~mm}$ $\mathrm{Sn}-3$ wt pet $\mathrm{Pb}$ alloy benchmark experiment presented in Fig. 1.

$\left(230{ }^{\circ} \mathrm{C}\right)$. However, for higher temperature shown in Figure 4(a), the temperature difference between the positions L21 and L30 cannot be reproduced with the 2D approximation. Only the 3D simulation shown in Figure 4(b) retrieves the measured temperature difference. This is a consequence of the velocity boundary layer forming along the two main vertical interfaces with the crucible. This effect is clearly not taken into account in the 2D calculation, leading to higher velocities. Also one can observe oscillations in the simulated cooling curves displayed in Figure 4(a). Detailed analysis shows that the 2D approximation does lead to an unsteady convective regime in the simulation domain, explaining these oscillations that are part of the converged solution of the FE problem.

A second set of simulations is now presented, which includes the prediction of the grain structure. Because of the obvious limitations of the $2 \mathrm{D}$ approximation for comparison with measurements, only 3D CAFE simulations are given. Additional simulation parameters to the FE solutions are given in the second part of Table I. Note that $T_{\mathrm{M}}$ is the melting temperature of pure $\mathrm{Sn}$ and is required to compute a local liquidus temperature at composition $\langle\mathrm{w}\rangle, T_{\mathrm{L}}=T_{\mathrm{M}}+m_{\mathrm{L}}\langle\mathrm{w}\rangle$. The liquidus slope, $\mathrm{m}_{\mathrm{L}}$, and the partition coefficient, $\mathrm{k}$, are only used to compute the velocity of the growth front with the CA model. These properties, deduced from the thermodynamic database given in Table I, were kept constant in the current simulations. This is justified when considering the hypoeutectic $\mathrm{Sn}-\mathrm{Pb}$ system shown in Figure 2. It was found sufficient to use a single nucleation law at the RHS surface of the simulation domain, i.e., where solidification starts because of cooling by the RHS heat exchanger. Parameters are labeled S_RHS. The value of $n_{\mathrm{Max}}^{\mathrm{S} R H \mathrm{~S}}$ permits one to achieve nucleation with a grain density similar to the one observed in the experiment. Other parameters are arbitrarily chosen to form the grain structure as soon as the liquidus is reached, i.e., within less than a degree around an average of $1.5 \mathrm{~K}$. Two different laws were used for nucleation in the melt. They are labeled V_I and V_II in Table I and correspond to the only difference between the two CAFE simulations presented hereafter. Nucleation law V_I permits more grains to nucleate than V_II $\left(n_{\text {Max }}^{\mathrm{V} \text { II }}=10 n_{\text {Max }}^{\mathrm{V} \text { II }}\right)$, with a smaller average undercooling $\left(\Delta T_{n}^{\mathrm{V} \_\mathrm{I}}<\Delta T_{n}^{\mathrm{V}-\mathrm{II}}\right)$.

Figure 5 presents the simulated fluid velocity at different times along with the computed grain structure, from start of solidification at 2400 seconds to its end at 5000 seconds. The latter times do not correspond to exact start and end of solidification and only chosen for the illustrations. A main convection loop is seen prior to and up to the start of solidification. It is mainly induced by the temperature difference between the LHS and RHS heat exchangers, thus initially corresponding to a natural convection induced by the temperature gradient. At 2400 seconds, measurements in Figure 4 reveal no 
(a)
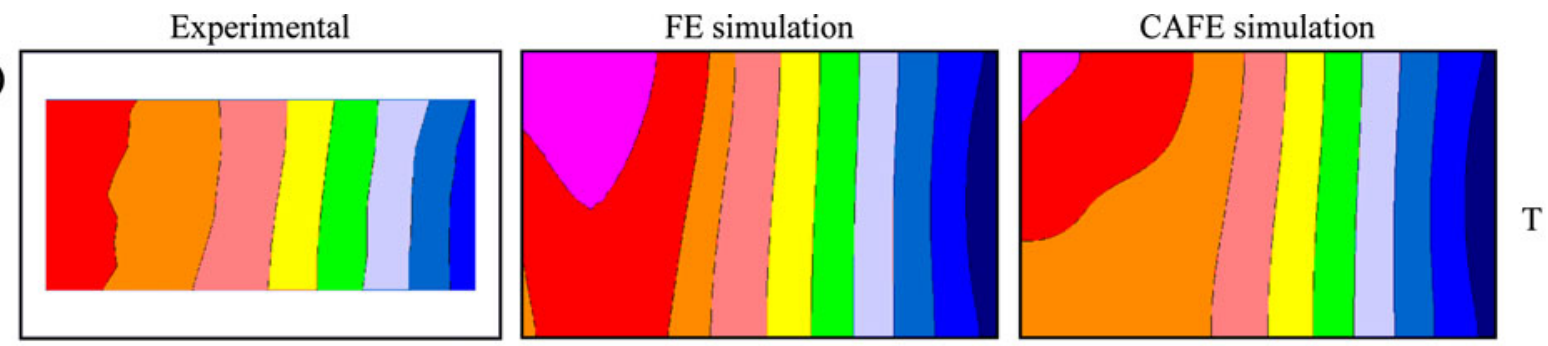

(b)

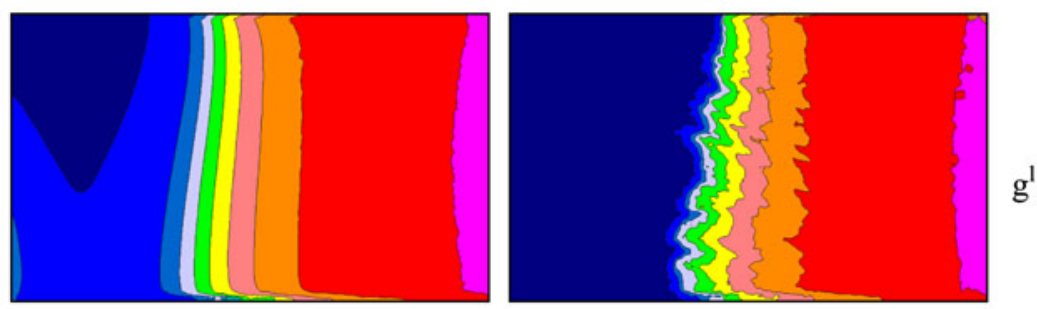

(c)

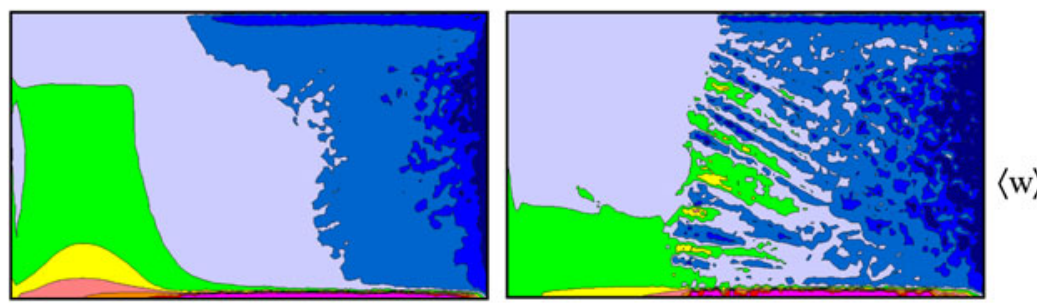

(d)

$\begin{array}{cccc}\mathbf{T}(\mathbf{K}) & \mathbf{T} \text { (Celsius) } & \mathbf{g}^{\mathbf{1}}(-\mathbf{)} & \langle\mathbf{w}\rangle \mathbf{( w t} \%) \\ -501.15 & 228 & 0.000 & 4.1 \\ -500.15 & 227 & 0.125 & 3.9 \\ -498.15 & 225 & 0.250 & 3.7 \\ -493.15 & 220 & 0.375 & 3.5 \\ -488.15 & 215 & 0.500 & 3.3 \\ -483.15 & 210 & 0.625 & 3.1 \\ -478.15 & 205 & 0.750 & 2.9 \\ -473.15 & 200 & 0.875 & 2.7 \\ -468.15 & 195 & 0.999 & 2.5\end{array}$

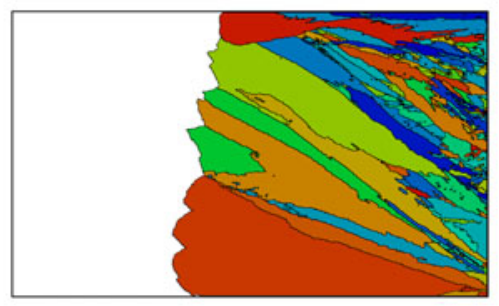

Fig. 6 - Comparison of mid-thickness 2D maps at time $t=3380 \mathrm{~s}$ (left) measured, (center) computed with the FE model, and (right) computed with the CAFE model for $(a)$ the temperature, $(b)$ the liquid fraction, and $(c)$ the average composition. The $2 \mathrm{D}$ metallographic cross section at mid-thickness shown in $(d)$ is only an output of the CAFE model.

temperature gradient in the melt between thermocouples L24 and L27, near the center of the domain. In fact, strong convection homogenizes the temperature at the center of the domain. In comparison, thermocouples L21 and L24 as well as L27 and L30 show clear differences that are maintained along the entire cooling sequence. In the liquid state, temperature gradient is thus only concentrated in the vicinity of the heat exchangers, as shown by comparing the temperature evolutions of FL $3_{\text {in }}$ and L21 as well as FR $3_{\text {in }}$ and L 30 , yet only at the distance of $5 \mathrm{~mm}$. From Figure 4, it is also clear that such behavior is only accessible through 3D simulations. Differences between L24 and L27 only start to appear when the solidification front reaches position L27 at about 2800 seconds. Then the liquid flow progressively vanishes, and cooling of L27 does significantly increases and departs from L24. The grain structure at 3000 seconds in Figure 5 is at an intermediate time after and before the captures of L24 and L27 by the growth front, respectively. Also in Figure 5 is clearly shown the strong interaction of the liquid flow with the development of the grain structure. The convection loop progressively moves toward the LHS hotter boundary of the domain upon growth of a columnar grain structure from the RHS cold boundary. During this displacement of the convection loop, fluid flow is maintained in the mushy zone, and its consequences on the development to macrosegregation will be shown later. Upon further cooling, the volume of liquid that becomes undercooled increases, while the temperature gradient in the melt increases. This is seen in Figure 4 by the decrease of the temperature difference between L21 and L24 before 3400 seconds. Nucleation of new grains can take place in the melt as shown at the time 3520 seconds in Figure 5.

A better comparison of the fields accessible by the various studies is given in Figure 6. The columns present the various methodologies of analysis, from (left) experimental to (right) CAFE simulation, with the intermediate (center) FE simulation. Only the temperature field is 


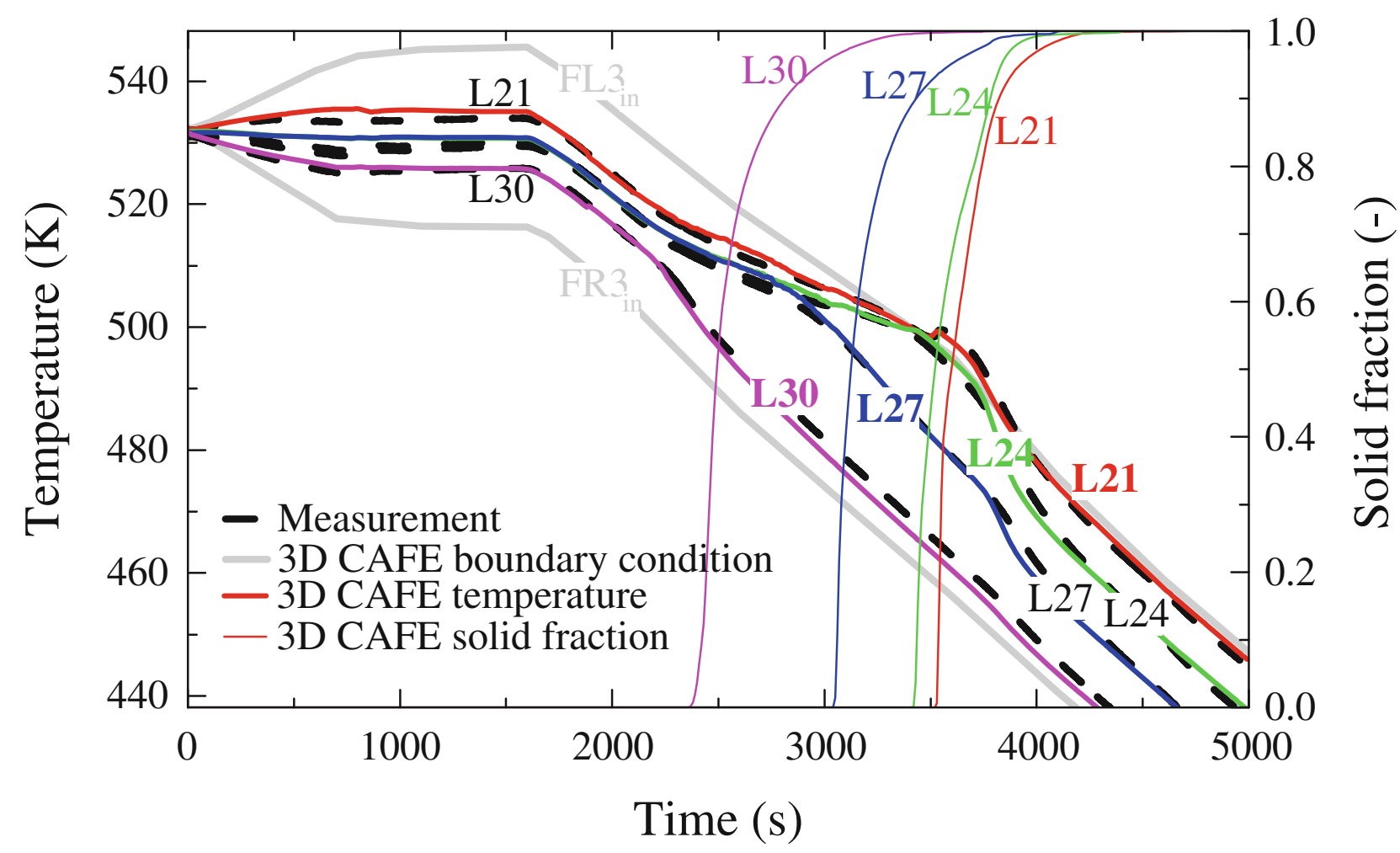

(a)

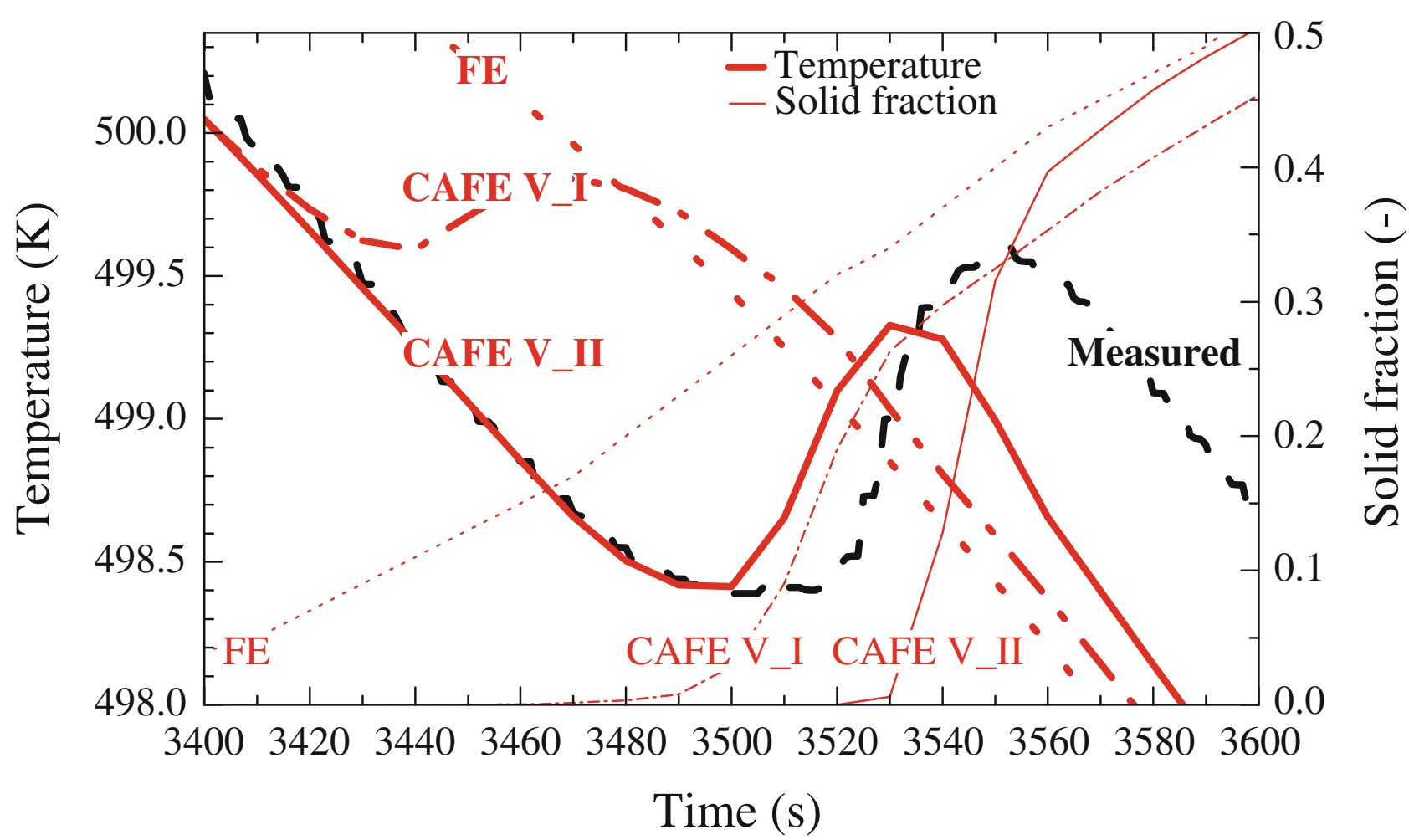

(b)

Fig. 7-Comparison of measured ${ }^{[12]}$ and computed cooling curves with $(a)$ the 3D CAFE model using nucleation law V_II in the volume. Magnification in $(b)$ reveals a detailed comparison for position L21 of a recalescence predicted by the CAFE simulation. Results are added for comparison, obtained with (doted lines) the FE model and (dashed and doted lines) the CAFE model with nucleation law V_I. The computed time evolutions of the total fraction of solid phases are added as thin lines. Values of the nucleation parameters are provided in Table I. 


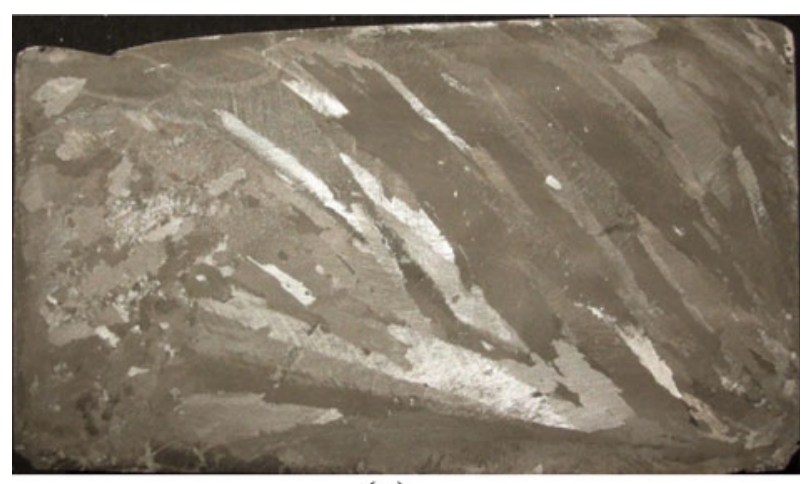

(a)

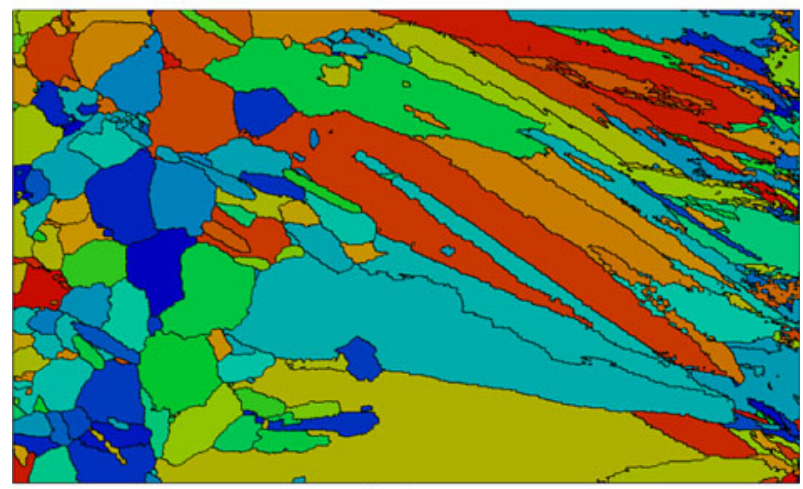

(b)

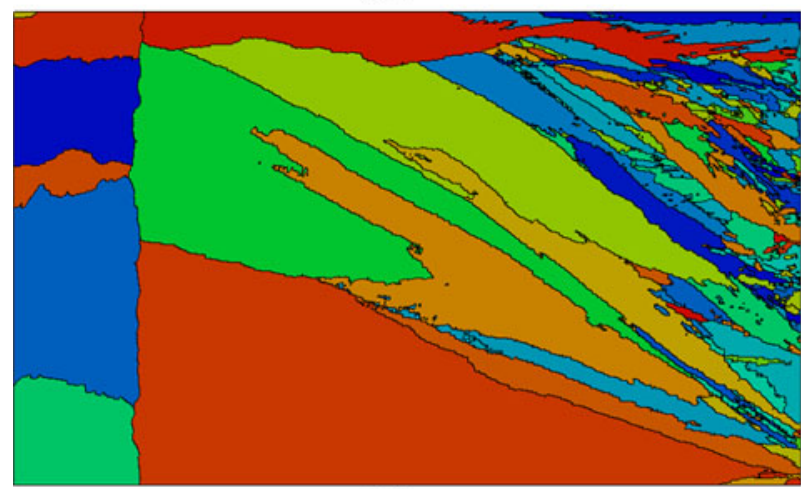

(c)

Fig. 8-Metallographic cross section at mid-thickness revealing the grain structure $(a)$ as observed on the ingot surface after etching, ${ }^{[12]}$ compared with 3D CAFE simulations with nucleation law in the volume $(b)$ V_I, and (c) V_II. Values of the nucleation parameters are provided in Table I.

accessible through direct measurements. It can be noticed that more field could be deduced from in-situ X-ray analyses, as previously demonstrated. ${ }^{[37-40]}$ While this is not the case in the current study, the experimental investigations are unique in the detailed measurements achieved that permit full time evolution of temperature maps within $\pm 1 \mathrm{~K}$. This difference permits the comparison presented in Figure 6. One could argue from comparing Figure 6(a) that little variations exist between FE and CAFE modeling, limited to less than a degree. However, it must be remembered that nucleation and growth of the grain structure take place at only few degrees below the liquidus isotherm. This is made visible in the representation of the fraction of the liquid phase in Figure 6(b).
While the CAFE simulation predicts a large zone of melt in front of the grain structure shown in Figure 6(d), it is significantly reduced with the FE simulation. The effect on the average composition map is shown in Figure 6(c).

Figure 7(a) compares measurements with the cooling curves predicted by means of a CAFE simulation. Results are very close to those of Figure 4(b). However, careful examination shows differences below the local liquidus temperature. In particular, at position L21, a recalescence is recorded. This is clearer upon magnification within the temperature range of 2.4 degrees shown in Figure 7(b). The local average composition is $3.08 \mathrm{wt}$ pct, and so the liquidus is $501.15 \mathrm{~K}\left(228.0{ }^{\circ} \mathrm{C}\right)$. At the maximum of the recalescence, the growth undercooling is consequently of the order of $2.8 \mathrm{~K}$. Note that the choice of the maximum temperature upon recalescence is done considering the plain curves labeled V_II in Figure 7(b), also corresponding to the simulation curves in Figure 7(a). The thick line is the predicted temperature, while the thin line is the predicted total solid fraction. The start of the recalescence takes place at about 3500 seconds, when location L21 is still fully liquid. The fraction of solid significantly departs from zero at 3525 seconds, when the temperature has reached its maximum. Thus, the growth undercooling at the time when the front passes through position L21 corresponds to the maximum of the recalescence. This observation is also in agreement with previous detailed analyses of heat flow upon growth of a mushy zone. ${ }^{[41]}$ The decrease of the temperature when the position is captured by the growth front corresponds to the preferential transport of the heat flow in the existing mushy zone. It should be pointed out that the order of magnitude for the undercooling, and the excellent comparison between the measured and predicted recalescence values provide an indirect validation of the dendrite tip kinetics model used in the current model. Simulation V_II corresponds to a low probability of nucleation in the melt. The final grain structure is accessible in Figure 8(c) as a metallographic cross section made at mid-thickness of the simulation domain. It is made of a columnar grain structure connected with the colder RHS and LHS boundaries of the simulation domain. While the simulated cooling curves are very close to measurements, the grain structure is significantly different from observation displayed in Figure 8(a). Consequently, nucleation parameters were modified as V_I. Results are given in Figure 7(b) as dashed doted lines and in Figure 8(b). The opposite is now found, with better prediction of the grain structure but poorer prediction of the temperature evolution upon recalescence. Indeed, recalescence starts earlier, at 3440 seconds, and also ends earlier at $3470 \mathrm{sec}-$ onds. It also takes place at a higher temperature and with a lower intensity. Several discussions can be found in the literature concerning the nucleation of grains ahead of a growing columnar front. ${ }^{[4-44]}$ They suggest the occurrence of fragmentation as the main mechanism for the formation of equiaxed grains ahead of a columnar structure for non inoculated melt, i.e., melt in which no particles have been added to enhance nucleation. These configurations are found here. Not only the melt was not inoculated by heterogeneous particles but also the liquid is fully undercooled, and reheating of a liquid is found 


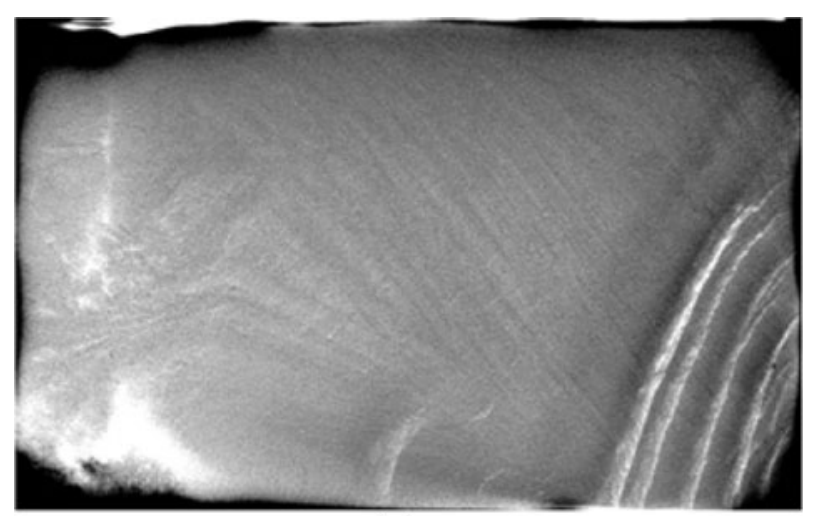

(a)

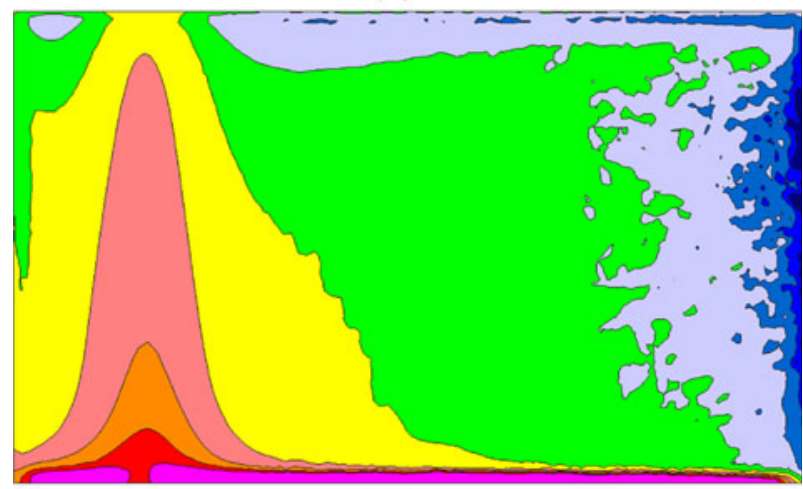

(b)

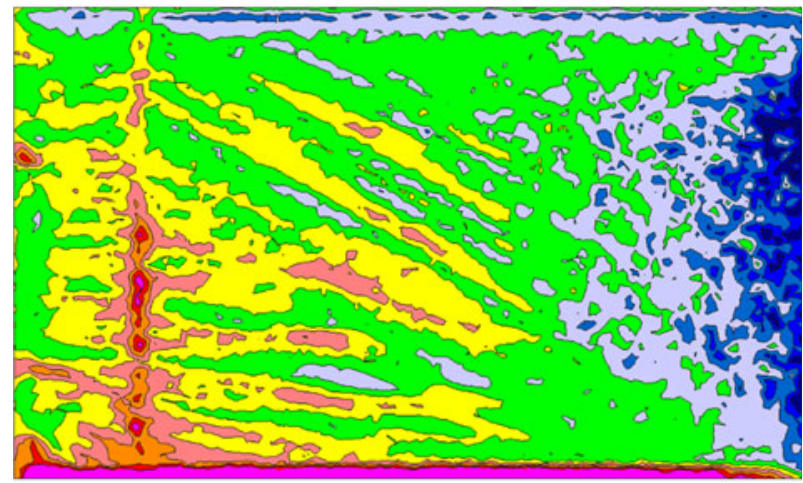

(c)

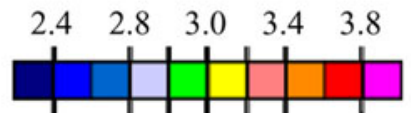

Fig. 9-Final segregation map $(a)$ as observed by X-ray analysis and predicted mid-thickness of the ingot by $(b)$ the 3D FE simulation, and $(c)$ the 3D CAFE simulation. The scale, with units in wt pct, only applies to predicted maps.

upon growth of a columnar front as attested by Figure 7(b). As a consequence, the columnar front is believed to slow down and internal remelting to take place. This is usually observed upon in situ investigations. ${ }^{[45,40]}$ The consequence of this discussion is the limitation of using Gaussian distribution of nucleation site to model equiaxed grain nucleation in unrefined alloys. A new methodology needs to be defined. In Figure 7(b), the simulation presented in Figure 4(b) has been added as doted lines. It is very clear that no

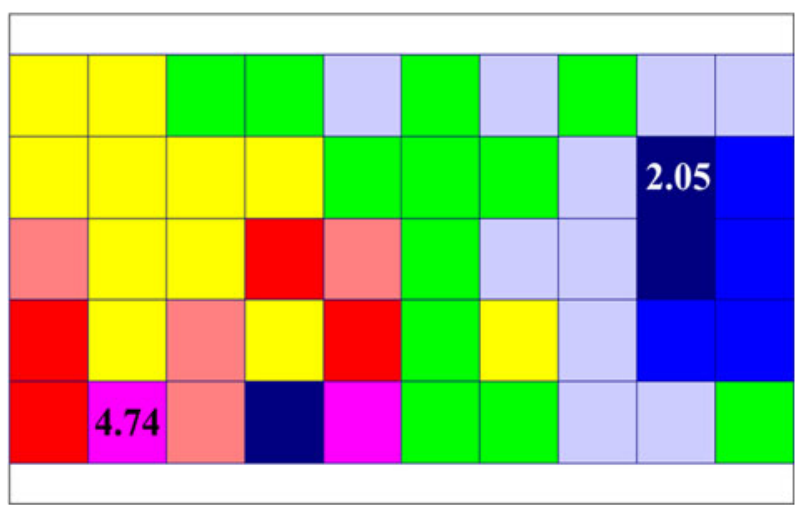

(a)

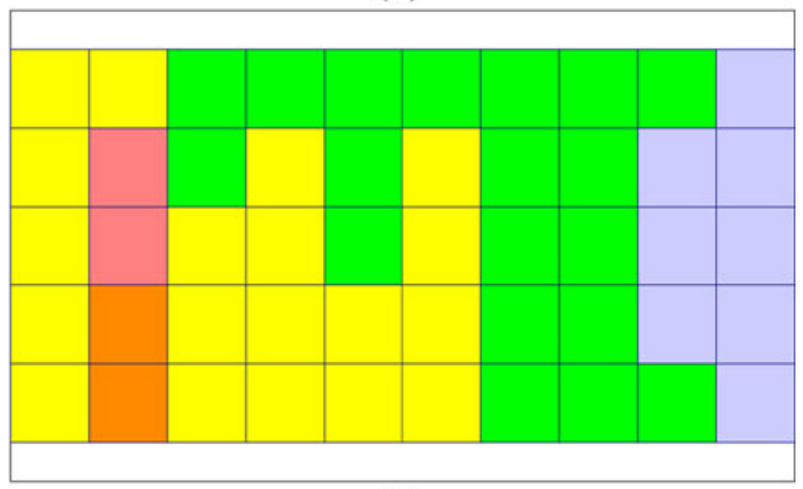

(b)

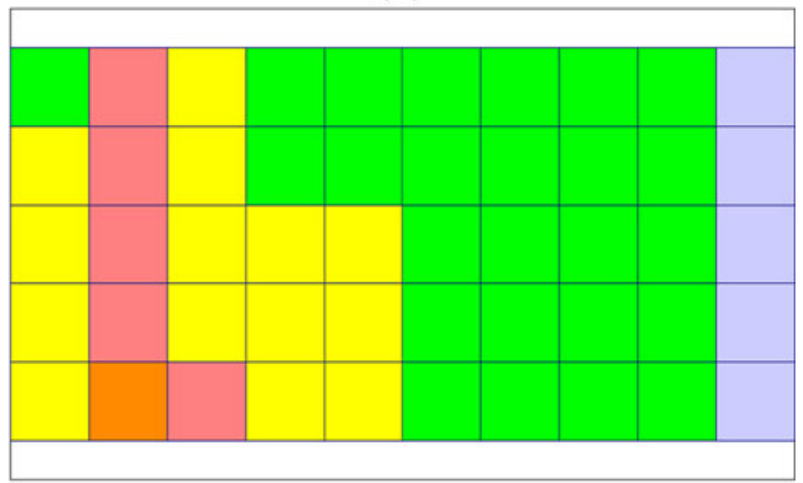

(c)

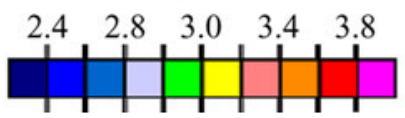

Fig. 10-Segregation map (a) as deduced from ICP measurements and predicted by $(b)$ the 3D FE simulation, and $(c)$ the 3D CAFE simulation. The scale, with units in wt pct, applies to all maps. The black rectangle is the total size of the casting.

recalescence is predicted. This is due to the construction of the model that does not authorize undercooling of the melt. As a consequence, the solid fraction departs from zero as soon as the local liquidus is reached. This takes place much before 3400 seconds as shown in Figure 7(b).

Average composition maps of the $\mathrm{Pb}$ solutal species are drawn in Figures 9 and 10. Parts (a) of the figures give access to measurements, while the computed maps are displayed in parts (b) for the FE simulation and in parts (c) for the CAFE simulation. As seen in the X-ray 
image of the ingot displayed in Figure 9(a), segregated channels are found at the bottom-right part of the ingot. $^{[12]}$ This is not predicted by the simulations. Although the reason for this discrepancy is not yet very clear, anisotropy of the mush permeability is suspected to play a role, while it is only treated as isotropic in the current model. The current 3D simulations might also require refinements with respect to mesh size to reach the level of prediction of segregated channels. A difference becomes yet obvious when comparing Figures 9(b) and (c): the segregated maps are less smooth when coupling with the development of the grain structure is achieved. This is also shown by comparison with Figure 6(c). In fact, the patterns of the channels predicted with the CAFE model are aligned with the main orientation of the grain structure shown in Figures 8(c) and 6(d). In this respect, it is also of interest to underline the overall upward inclined growth direction of the grains. It corresponds to the installation of a texture due to the dependence of the growth undercooling with the crystallographic orientation of each individual grain. The reason for this is attributable to the introduction of the fluid flow direction with respect to the $\langle 100\rangle$ growth directions of the grains for the computation of the growth kinetic in Eqs. [5] through [7]. Because the flow shown in Figure 5 is going downward along the growth front, the growth directions of the grains that are opposite to the flow can adopt a smaller undercooling. They extend faster in the undercooled liquid and lead to the current grain selection and texture. While this correlates well with observations given in Figure 8(a), the direction of the grains does not exactly retrieve the misorientation. It is not clear whether this is due to the kinetic law itself or to the growth algorithm implemented in the CA method. Further investigations should be led in this direction, which would probably require more dedicated experiments and characterizations. Although the X-ray map is not made quantitative and can only be qualitatively compared with simulations, it is clear that the high intensity of the gray level corresponding to the accumulation of $\mathrm{Pb}$ is well retrieved at the bottom-left part. In fact, more quantitative comparison is achieved in Figure 10 thanks to the ICP measurements. From the computed maps given in Figures 9(b) and (c), 2-mm diameter cylinders are drilled through the entire ingot's thickness, which are centered at the position of the thermocouples. The results shown in Figures 10(b) and (c) reveal little differences and retrieve the trends of the measurements shown in Figure 10(a). At this level of averaging, the segregated patterns shown in Figure 9(b) are not visible anymore. Also, the minimum and maximum values measured, as given in Figure 10(a), are not yet retrieved by the simulations.

As mentioned in the introduction, several origins are often encountered in the literature to explain the formation of macrosegregation. The current model accounts mainly for solute transport because of fluid flow and segregation of species between the solid and liquid phases. Hence, the transport of the grain structure due to gravity and convection is not implemented in the CAFE model, despite its feasibility having been demonstrated in a previous study, ${ }^{[19]}$ or is the effect of deformation and shrinkage. The transport of the grains can be reasonably neglected in the current benchmark experiment because the structure is mainly of columnar nature. As previously discussed, the equiaxed grains seen in the LHS of the macrograph shown in Figure 8(a) are thought to originate from fragmentation of the columnar dendritic front when it slows down and propagates in a liquid with no temperature gradient. If this is the case, the equiaxed grains are formed very close to the growth front and are likely to experience very small transport. The effect of the density variations between the solid and liquid phases on macrosegregation is not as easy to estimate. It yet appears clearly at the top of Figure 8(a) where shrinkage can be quantified by the departure of the ingot contour from the rectangular cavity shape. As explained in the introduction, shrinkage-driven flow is also known as the source of macrosegregation. ${ }^{[2-7]}$ Hence, implementation of such effect, and its coupling with the formation of the grain structure is clearly a perspective for the current modeling approach.

\section{CONCLUSIONS}

A 3D CAFE model is presented and applied to a macrosegregation benchmark experiment. It includes a FE solution for heat and mass transport in the presence of fluid flow, with differentiation of total mass and solute mass, coupled with a CA prediction of the grain structure and tabulation of thermodynamic properties. The model is able to reach very good comparison with measured cooling curves. In particular, the occurrence of undercooled regions and recalescence are predicted. Advantages with purely $2 \mathrm{D}$ and $3 \mathrm{D}$ FE models that do not include coupling with the prediction of the grain structure are evidenced. The agreement is found reasonably good regarding the macrosegregation map and the grain structure observed in a metallographic cross section. However, prediction of segregated channels observed in X-ray imaging of the as-cast ingot is still below expectations and may, therefore, require additional resources and model improvements.

\section{ACKNOWLEDGMENTS}

This study was funded by the French National Research Agency under projects SMACS (ANR-07BLAN-0190) and Si-X (ANR-08-HABISOL-012-04), as well as by the European Space Agency under project CETSOL (ESA-4200014313).

\section{REFERENCES}

1. C. Beckermann: Int. Mater. Rev., 2002, vol. 47, pp. 243-61.

2. M.C. Flemings and G.E. Nereo: Trans. Metall. Soc. AIME, 1967, vol. 239, pp. 1449-61.

3. M.C. Flemings, R. Mehrabian, and G.E. Nereo: Trans. Metall. Soc. AIME, 1968, vol. 242, pp. 41-49.

4. M.C. Flemings and G.E. Nereo: Trans. Metall. Soc. AIME, 1968, vol. 242 , pp. 50-55.

5. R. Mehrabian and M.C. Flemings: Trans. Metall. Soc. AIME, 1969, vol. 245, pp. 2347-48.

6. R. Mehrabian, M. Keane, and M.C. Flemings: Metall. Trans., 1970, vol. 1, pp. 1209-20. 
7. M.C. Flemings, R. Mehrabian, and M. Keane: Metall. Trans., 1970, vol. 1, pp. 3238-41.

8. D.J. Hebditch and J.D. Hunt: Metall. Trans., 1974, vol. 5, pp. 1557-64.

9. G. Lesoult, Ch.-A. Gandin, and N.T. Niane: Acta Mater., 2003, vol. 51, pp. 5263-83.

10. D.J. Hebditch: Ph.D. Thesis, University of Oxford, Oxford, 1973.

11. X.D. Wang and Y. Fautrelle: Int. J. Heat Mass Transf., 2009, vol. 52, pp. 5624-33.

12. L. Hachani, B. Saadi, X.D. Wang, A. Nouri, K. Zaidat, A. Belgacem Bouzida, L. Ayouni-Derouiche, G. Raimondi, and Y. Fautrelle: Int. J. Heat Mass Transf., 2012, vol. 55, pp. 1986-96.

13. Ch.-A. Gandin, J. Blaizot, S. Mosbah, M. Bellet, G. Zimmermann L. Sturz, D.J. Browne, S. McFadden, H. Jung, B. Billia, N. Mangelinck, H. Nguyen Thi, Y. Fautrelle, and X. Wang: Mater. Sci. Forum, 2010 , vol. 649, pp. 189-98.

14. Ch.-A. Gandin and M. Rappaz: Acta Mater., 1997, vol. 45, pp. $2187-95$.

15. Ch.-A. Gandin, J.L. Desbiolles, M. Rappaz, and Thevoz. Ph: Metall. Mater. Trans. A, 1999, vol. 30A, pp. 3153-65.

16. H. Takatani, Ch.-A. Gandin, and M. Rappaz: Acta Mater., 2000 , vol. 48 , pp. $675-88$.

17. P. Carter, D.C. Cox, Ch.-A. Gandin, and R.C. Reed: Mater. Sci. Eng., 2000, vol. A280, pp. 233-46.

18. G. Guillemot, Ch.-A. Gandin, H. Combeau, and R. Heringer: Modell. Simul. Mater. Sci. Eng., 2004, vol. 12, pp. 545-56.

19. G. Guillemot, Ch.-A. Gandin, and H. Combeau: ISIJ Int., 2006 , vol. 46, pp. 880-95.

20. G. Guillemot, Ch.-A. Gandin, and M. Bellet: J. Cryst. Growth, 2007, vol. 303, pp. 58-68.

21. S. Mosbah, M. Bellet, and Ch.-A. Gandin: Metall. Mater. Trans. A, 2010, vol. 41A, pp. 651-69.

22. Ch.-A. Gandin: C.R. Phys., 2010, vol. 11, pp. 216-25.

23. T. Carozzani, H. Digonnet, and Ch.-A. Gandin: Modell. Simul. Mater. Sci. Eng., 2012, vol. 20, p. 015010.

24. J. Ni and C. Beckermann: Metall. Mater. Trans. B, 1991, vol. 22B, pp. 349-61.

25. J.A. Dantzig and M. Rappaz: Solidification, EPFL Press, Lausanne, $\mathrm{CH}, 2009$

26. S.D. Felicelli, J.C. Heinrich, and D.R. Poirier: Metall. Mater. Trans. B, 1991, vol. 22B, pp. 847-59.
27. S.D. Felicelli, J.C. Heinrich, and D.R. Poirier: J. Cryst. Growth, 1998, vol. 191, pp. 879-88.

28. J.C. Ramirez and C. Beckermann: Metall. Mater. Trans. A, 2003, vol. 34A, pp. 1525-36.

29. B. Rivaux: Ph.D. Thesis, MINES ParisTech, Paris, FR, 2011.

30. K. Sabat Da Cruz, N. Mangelinck-Noël, Ch.-A. Gandin, and B. Billia: IOP Conf. Ser.: Mater. Sci. Eng., 2011, vol. 27, p. 012017.

31. Ch.-A. Gandin, G. Guillemot, B. Appolaire, and N.T. Niane: Mater. Sci. Eng., A, 2003, vol. 342, pp. 44-50.

32. R. Trivedi and W. Kurz: Int. Mater. Rev., 1994, vol. 39, pp. 49-74.

33. M. Ben Amar and E. Brener: Phys. Rev. Lett., 1993, vol. 71, pp. 589-92.

34. D. Tourret and Ch.-A. Gandin: Acta Mater., 2009, vol. 57, pp. 2066-79.

35. D. Tourret, Ch.-A. Gandin, T. Volkmann, and D.M. Herlach: Acta Mater., 2011, vol. 59, pp. 4665-77.

36. D. Tourret, G. Reinhart, Ch.-A. Gandin, G.N. Iles, U. Dahlborg, M. Calvo-Dahlborg, and C.M. Bao: Acta Mater., 2011, vol. 59, pp. 6658-69.

37. H. Yin and J.N. Koster: J. Alloys Compd., 2003, vol. 352, pp. 197209.

38. N. Shevchenko, Eckert.S. Boden, and G. Gerbeth: IOP Conf. Ser. Mater. Sci. Eng., 2012, vol. 27, p. 012085.

39. A. Bogno, H. Nguyen-Thi, A. Buffet, G. Reinhart, B. Billia, N. Mangelinck-Noël, N. Bergeon, J. Baruchel, and T. Schenk: Acta Mater., 2011, vol. 59, pp. 4356-65.

40. R.H. Mathiesen and L. Arnberg: Acta Mater., 2005, vol. 53, pp. 947-56.

41. R. Heringer, Ch.-A. Gandin, G. Lesoult, and H. Henein: Acta Mater., 2006, vol. 54, pp. 4427-40.

42. Ch.-A. Gandin: ISIJ Int., 2000, vol. 40, pp. 971-79.

43. Ch.-A. Gandin: Acta Mater., 2000, vol. 48, pp. 2483-2501.

44. M.A. Martorano, C. Beckermann, and Ch.-A. Gandin: Metall. Mater. Trans. A, 2003, vol. 34, pp. 1657-74.

45. K.A. Jackson, J.D. Hunt, D.R. Uhlmann, and T.P. Seward: Trans. AIME, 1966, vol. 236, pp. 149-58.

46. Thermo-Calc: Version $S$, Thermo-Calc Software AB, Stockholm, SE, 2010.

47. PBIN: Public Binary Alloys Thermodynamic Database, version 1.2. Thermo-Calc Software AB, Stockholm, SE, 2008. 